\title{
MONEY AND CREDIT REDUX
}

\section{BY CHAO GU, FABRIZIO MATTESINI, AND RANDALL WRIGHT ${ }^{1}$}

\begin{abstract}
We analyze money and credit as competing payment instruments in decentralized exchange. In natural environments, we show the economy does not need both: if credit is easy, money is irrelevant; if credit is tight, money is essential, but credit becomes irrelevant. Changes in credit conditions are neutral because real balances respond endogenously to keep total liquidity constant. This is true for both exogenous and endogenous debt limits and policy limits, secured and unsecured lending, and general pricing mechanisms. While we show how to overturn some of these results, the benchmark model suggests credit might matter less than people think.
\end{abstract}

KEYWORDS: Money, credit, debt, essentiality, neutrality.

"Of all branches of economic science, that part which relates to money and credit has probably the longest history and the most extensive literature." Lionel Robbins, Introduction to von Mises (1953).

\section{INTRODUCTION}

IN RELATIVELY TURBULENT FINANCIAL TIMES, it is no surprise that many economists are trying to better understand money, credit, liquidity, and related topics. Some of us have been studying these things all along, however, and this essay is an attempt to communicate salient aspects of our methods, as well as to illustrate the kinds of insights that emerge in terms of policy implications. A primary goal is to develop a framework that can be used to study the relationship between money and credit in their roles as competing payment instruments. As is well known, it is not easy to integrate money into equilibrium theory, especially when credit is an option. Our approach involves describing an environment incorporating frictions like spatial or temporal separation plus, importantly, imperfect information and limited commitment. Then, we model agents as trading with each other as in search theory, instead of merely picking

\footnotetext{
${ }^{1}$ A version of this paper was delivered as the Fisher-Schultz Lecture at the 2014 Econometric Society European Meetings in Toulouse, France, by Randall Wright. We thank everyone involved in this event for their support. We also thank for their input Luis Araujo, Gadi Barlevy, Jess Benhabib, Cyril Monnet, Guillaume Rocheteau, Francesco Lippi, Tai-Wei Hu, Yu Zhu, John Kennan, and Peter Norman, as well as participants in workshops and conferences in Basel, Science Po (Paris), UC-Irvine, Edinburgh, Singapore, Wisconsin, the Federal Reserve Banks of Chicago and Minneapolis, the IIES and Riksbank in Stockholm, Rome Tor-Vergata, and the Bank of Italy. The editor and four anonymous referees also made some excellent suggestions that shaped the motivation and presentation in the revision. Gu thanks the Economic and Policy Analysis Research Center at the University of Missouri for research support. Wright thanks the NSF and the Ray Zemon Chair in Liquid Assets at the Wisconsin School of Business for support on this and related research. The usual disclaimers apply.
} 
points in their budget sets as in traditional general equilibrium theory. This allows us to think seriously about alternative payment arrangements. ${ }^{2}$

The main result is this: in a variety of environments, in equilibrium where money is valued, credit is inessential and changes in credit conditions are neutral. By essential we mean that the set of equilibria, or the set of incentivefeasible allocations, is bigger or better with an institution than without it. ${ }^{3}$ By credit conditions, in the baseline model, we mean debt limits, although extensions also consider the monitoring of default and the pledgeability of assets. In monetary equilibrium, tightening the debt limit is neutral-it has no impact on allocations or welfare-and, as a special case, shutting down credit does not matter, making it inessential. We demonstrate this using versions of the most popular modern theories of credit markets, including those with unsecured lending following Kehoe and Levine (1993), and those with collateralized lending following Kiyotaki and Moore (1997). These results may be surprising, but they can be understood by noticing that the real value of money adjusts endogenously to changes in debt limits so that total liquidity remains the same-something one would miss if one concentrated solely on models without money.

To put this in perspective, it helps to consider some well-known economic propositions. In finance, the Modigliani-Miller theorem says it does not matter if firms issue debt or equity; in macro, Ricardian equivalence says it is irrelevant whether governments tax or run a deficit to be settled later; and in international, Kareken-Wallace indeterminacy says any exchange rate between two currencies can be an equilibrium. Our propositions are similar in spirit, if not stature, in the following sense: there may be situations where they do not apply, as discussed below, but even if one can find "loopholes" (changes in specifications to get around the results), they still contain strong elements of truth. One may believe that, in reality, firms care about the option to issue equity or debt, the current deficit matters, or exchange rates are pinned down by market forces; that does not render these famous irrelevance results irrelevant. Similarly, whether or not credit conditions matter in reality, theory implies they do not matter in several natural settings. Hence, we think, to substantiate the position that debt limits (corporate finance, deficit spending, or

\footnotetext{
${ }^{2}$ The approach is sometimes dubbed New Monetarist Economics, for reasons articulated in Williamson and Wright (2010a), although discussing labels may be less important than describing the motivation and models in the literature. On that, see Shi (2006), Wallace (2001, 2010), Williamson and Wright (2010b), Nosal and Rocheteau (2011), and Lagos, Rocheteau, and Wright (2015).

${ }^{3}$ The notion that it is important to ask whether money is essential goes back to Frank Hahn. For research that pursues this idea, and also discusses the essentiality of credit, bonds, banking, or intermediation, see Townsend (1987, 1988), Kocherlakota (1998), Wallace (2001, 2010), Mills (2007), Aliprantis, Camera, and Puzzello (2007), Araujo and Minetti (2011), Berentsen and Waller (2011), Araujo, Camargo, Minetti, and Puzzello (2012), Gu, Mattesini, Monnet, and Wright (2013a), Araujo and Hu (2014), and Nosal, Wong, and Wright (2014).
} 
exchange rates) matter, one should be able to say how and why the benchmark results do not apply. ${ }^{4}$

For studying money and credit as substitutes in the payment process, we think the background environment used here-a generalization of Lagos and Wright (2005) or Rocheteau and Wright (2005) — is the best available, even if it may be less natural for thinking about different types of credit (e.g., mortgages, student loans, or other ways of smoothing consumption over the life cycle). The framework for our purposes has these virtues: (i) It builds on what is now standard monetary theory. (ii) It is tractable and delivers sharp analytic results. (iii) It flexibly incorporates elements of search and general equilibrium theory. (iv) It accommodates a large class of pricing mechanisms, including bargaining, price taking, posting, etc. The last feature is crucial for understanding some issues; for example, if feasible, the Friedman rule is typically an optimal policy, as in many models, but here it achieves first-best efficiency for some mechanisms, such as Walrasian pricing or Kalai bargaining, and not others, such as Nash bargaining. These are among the reasons we choose to prove the results in this particular environment, even if they may well be more general. ${ }^{5}$

To paraphrase the results, if credit is easy, money is irrelevant, while if credit is tight, money is essential but credit is irrelevant. We prove this when debt limits are exogenous, or endogenous as in Kehoe and Levine (1993), and when policy limits are exogenous, or endogenous as in Andolfatto (2013). We consider unsecured credit, and secured credit as in Kiyotaki and Moore (1997), and we consider the case where debt limits can be relaxed at a cost, as in Bethune, Choi, and Wright (2015). Also, following Wong (2015), we use a relatively if not completely general class of preferences. This suggests the idea

\footnotetext{
${ }^{4}$ At the risk of overkill, the welfare theorems provide another example: While it is easy to say the assumptions are not literally true, the counterpoint is to ask people claiming the market fails to explain how and why it fails in the context of a question at hand.

${ }^{5}$ We think we could prove versions of our results in monetary environments like Bewley (1980) or Wallace (1980), suitably modified to admit credit, the way we modify Lagos and Wright (2005) below, although it may be less easy in those models. Similarly, versions should hold in a banking model like Diamond and Dybvig (1983), once one embeds it in monetary general equilibrium, as in Berentsen, Camera, and Waller (2007) or Williamson (2012). We also conjecture the results would apply to formulations like Bernanke and Gertler (1989) or Gertler and Kiyotaki (2010), at least if they could be integrated rigorously into general equilibrium monetary theory. But to be clear, these are conjectures at this stage. In terms of other models, those that impose an exogenous partition of commodity space into cash goods and credit goods, like Lucas and Stokey (1987), are not useful for our purposes. Slightly better are setups with intrinsic properties favoring some instruments over others-for example, He, Huang, and Wright $(2005,2008)$ and Sanches and Williamson (2010) assumed cash is subject to theft while credit or bank deposits are not, while Kahn, McAndrews, and Roberds (2005) and Kahn and Roberds (2008) assumed the opposite (Nosal and Rocheteau (2011) discussed related work). This transactions-cost approach is interesting, and may change some of the results, just like it can for Modigliani-Miller, KarakenWallace, or Ricardian equivalence, but for the most part we want to give money and credit equal opportunities. However, we emphasize in Section 6.1 that transactions costs do not necessarily change the results.
} 
is somewhat robust, and thus relevant for policy. While we also provide alternative assumptions that yield different results, a general message is that those working with nonmonetary theories should check if their findings about credit survive the introduction of currency, since in several specifications we find higher debt limits merely crowd out real balances. Even without this strong neutrality result, a more general message is that credit conditions have very different effects in monetary and nonmonetary economies, and this ought not be ignored in policy analysis.

Independent of policy considerations, as mentioned above, as a matter of pure theory it is challenging to model money and credit together, because assumptions adopted to make one viable often make the other untenable. Kocherlakota (1998) showed money is inessential if credit can be supported with commitment or enforcement. Further, he showed money is inessential even without commitment if there is perfect information-monitoring and record keeping-about actions, since then agents who renege on obligations can be punished and this can allow credit without commitment. So, any theory of essential money must have limited information as well as limited commitment. This is the case in models along the lines of Kiyotaki and Wright (1989, 1993), but there the frictions completely preclude credit. Models along the lines of Kehoe and Levine $(1993,2001)$ generate endogenous debt limits, but do not allow currency, with a few exceptions mentioned in footnote 14 below. Our goal is to combine elements of these literatures to see how money and credit interact. To summarize, we study the use of money and credit in decentralized exchange, where limits to debt and policy can be endogenous, in economies with commitment and information frictions, as well as a general class of pricing mechanisms.

Section 2 presents the environment. Section 3 proves benchmark results with exogenous policy and debt limits. Section 4 endogenizes policy and debt limits. Section 5 considers extensions. Section 6 concludes. In terms of the literature, there is too much work on money and credit to survey here, so we mention only that which is directly related; for the rest, see the papers mentioned above and references therein.

\section{ENVIRONMENT}

Time is discrete and continues forever. In each period, two markets convene sequentially: first, there is a decentralized market, or DM, with frictions detailed below; then there is a frictionless centralized market, or CM. In the CM, a large number of infinitely lived agents work, consume, adjust their portfolios, and settle their debt/tax obligations, or renege on these obligations, as the case may be. In the DM, some of the agents, called sellers and denoted by $s$, can produce but do not consume, while others, called buyers and denoted by $b$, want to consume but cannot produce. Buyers and sellers in the DM trade bilaterally 
in the baseline model, meeting randomly, with $\alpha$ denoting the probability that a buyer meets a seller. ${ }^{6}$

The within-period utility functions of buyers and sellers are

$$
\mathcal{U}^{b}=u(q)+U^{b}(x, 1-\ell) \text { and } \mathcal{U}^{s}=-c(q)+U^{s}(x, 1-\ell),
$$

where $q$ is the DM good, $x$ is the CM good, and $\ell$ is labor so $1-\ell$ is leisure. Assume that 1 unit of $\ell$ produces $\omega$ units of $x$, where $\omega$ is a fixed parameter, to pin down the CM real wage (this is relaxed below). The constraints $x \geq 0$, $q \geq 0$, and $\ell \in[0,1]$ are assumed not to bind, as can be guaranteed in the usual ways. Also, $U^{j}, u$, and $c$ are twice continuously differentiable and strictly increasing. Assume $U^{\prime \prime} \leq 0, u^{\prime \prime} \leq 0 \leq c^{\prime \prime}$ with one equality strict, and $u(0)=$ $c(0)=0$. The usefulness of the following restriction on CM utility, adopted from Wong (2015), will be clear below:

ASSUMPTION 1: $\left|U^{j}\right|=0$, where $|U|=U_{11} U_{22}-U_{12}^{2}$.

This is true for any quasi-linear utility function $U=\tilde{U}(x)-\ell$ or $U=$ $x+\tilde{U}(1-\ell)$, and for any utility function that is homogeneous of degree 1 , including, for example, $U=x^{a}(1-\ell)^{1-a}$ and $U=\left[x^{a}+(1-\ell)^{a}\right]^{1 / a}$.

There is discounting between the CM and DM according to $\beta=1 /(1+r)$, $r>0$; any discounting between the DM and CM can be subsumed in the notation in (1). Goods $q$ and $x$ are nonstorable. There is an intrinsically worthless object called money that is storable; other storable assets are introduced below. The money supply per buyer $M$ changes over time at rate $\pi$, so that $M_{+1}=(1+\pi) M$, where the subscript +1 (or -1$)$ on a variable indicates its value next (or last) period. Changes in $M$ are accomplished by lump-sum transfers if $\pi>0$ and lump-sum taxes if $\pi<0$. We restrict attention to $\pi>\beta-1$, or the limit $\pi \rightarrow \beta-1$, which in this setting corresponds to the Friedman rule; there is no monetary equilibrium with $\pi<\beta-1$.

There are two standard ways to model intertemporal exchange. One is to have a desire by agents to smooth consumption in the presence of fluctuating resources. The other is to have a desire to satisfy random consumption needs or opportunities. We use the latter, although any asynchronization of resources and expenditures would work. In our DM, with probability $\alpha$, buyers have opportunities to get $q$ from sellers, and the focus is on the payment

\footnotetext{
${ }^{6}$ In this setting, based on Rocheteau and Wright (2005), buyer and seller types are permanent, and the measure of each is fixed, although either assumption is easy to relax. Also, as discussed there and mentioned below, we can alternatively let agents trade multilaterally in the DM. In terms of random matching, it is not hard to endogenize $\alpha$ by specifying a general meeting technology, with or without participation decisions on either side of the market. Also, instead of having buyers in the DM meet randomly, we can alternatively say $\alpha$ is the probability of a preference shock, and buyers hit with the shock visit sellers, using either directed or undirected search, at which point they trade, either bilaterally or multilaterally. The results are basically the same.
} 
method, cash or credit. Credit means a promise of numeraire in the next CM. Because there is no commitment or enforcement, generally, we need to incorporate punishments for those who renege on promises. As in Kehoe and Levine (1993), this puts restrictions on debt. The same considerations apply to taxes: agents can renege on public obligations, like private obligations, with similar consequences. As in Andolfatto (2013), this puts restrictions on deflation.

Different punishments can be considered, but as a benchmark, those caught reneging move to future autarky. As in Gu et al. (2013a, 2013b), reneging is monitored, and hence punished, randomly. One interpretation is this: If you fail to pay taxes, the fiscal authorities see this only if they audit you, which happens with some probability. Similarly, debtors pay into a common fund that is disbursed to lenders, and your failure to contribute is only noticed if the credit authorities audit you. Whatever the story, we need monitoring to be possible but not perfect to have a hope of getting both money and credit used in equilibrium, as discussed further in Section $5 .^{7}$

\section{EXOGENOUS POLICY AND DEBT LIMITS}

We first study equilibrium for given limits to debt and deflation. This may be of interest in its own right, and is a stepping stone toward endogenizing these limits.

\subsection{The CM Problem}

The state of an agent in the CM is his wealth, $A=\phi m-d-T$, where $\phi$ is the value of his money $m$, in terms of numeraire $x, d$ is debt, and $T$ is a lumpsum tax. For convenience in notation, only buyers pay $T$, not sellers. Debt, which comes from the previous DM, is paid off in the current CM (we could let agents roll it over, given the usual conditions to rule out Ponzi schemes, without changing the main results). The value functions in the CM and DM are $W(A)$ and $V(\phi m)$. Until Section 6 , we focus on stationary outcomes where real variables are constant, including $\phi M$. This means that $\phi / \phi_{+1}=1+\pi$ is the rate of inflation as well as the rate of monetary expansion. It also means that $W(\cdot)$ and $V(\cdot)$ are time invariant.

The CM problem for an agent of type $j=b, s$ (buyer or seller) is

$$
W_{j}(A)=\max _{x, \ell, \hat{m}}\left\{U^{j}(x, 1-\ell)+\beta V_{j}\left(\phi_{+1} \hat{m}\right)\right\} \quad \text { s.t. } \quad A+\omega \ell=x+\phi \hat{m} .
$$

\footnotetext{
${ }^{7}$ As Wallace (2013) said, "If we want both monetary trade and credit in the same model, we need something between perfect monitoring and no monitoring. As in other areas of economics... extreme versions are both easy to describe and easy to analyze. The challenge is to specify and analyze intermediate situations." The random monitoring assumption is our way of capturing an "intermediate situation" that proved very useful in past work.
} 
Let $x=x(A), \ell=\ell(A)$, and $\hat{m}=\hat{m}(A)$ be a solution, satisfying the FOC's

$$
\begin{aligned}
& \omega U_{1}^{j}(x, 1-\ell)-U_{2}^{j}(x, 1-\ell)=0, \\
& A+\omega \ell-\phi \hat{m}-x=0, \\
& -\phi U_{1}^{j}(x, 1-\ell)+\beta \phi_{+1} V_{j}^{\prime}\left(\phi_{+1} \hat{m}\right) \leq 0, \quad=\quad \text { if } \quad \hat{m}>0 .
\end{aligned}
$$

Sellers choose $\hat{m}_{s}=0$, because they have no need to bring liquidity into the DM. For buyers, $\hat{m}=\hat{m}_{b}>0$ in monetary equilibrium (as defined formally below; for now it simply means a situation with $\phi>0$ ).

Assumption 1 implies several results that greatly simplify the analysis:

LEMMA 1: Given an interior solution for $x(A)$ and $\ell(A), \hat{m}_{j}^{\prime}(A)=0$.

Lemma 2: Let $\Lambda_{j}(A)=U_{1}^{j}[x(A), 1-\ell(A)]$. Then $W_{j}^{\prime}(A)=\Lambda_{j}(A)$ and $\Lambda_{j}^{\prime}(A)=0$. Let $U_{0}^{j}=U^{j}[\omega \ell(0), 1-\ell(0)]$. Then $U^{j}[\omega \ell(A)+A, 1-\ell(A)]=$ $U_{0}^{j}+\Lambda_{j} A$.

Proofs are in the Appendix. In terms of substance, Lemma 1 says all buyers take the same $\hat{m}$ out of the CM, independent of $A$, and hence the $m$ they brought in, which means we do not have to track the distribution of $\hat{m}$ across buyers in the DM as a state variable. Lemma 2 says CM payoffs are linear in wealth. ${ }^{8}$

\subsection{The DM Problem}

With probability $\alpha$, a buyer meets a seller in the DM, whence they must choose a quantity $q$ and payment $p$. This choice is subject to $p \leq L$, where $L=D+\phi m$ is the liquidity position of the buyer, given by his debt limit plus real balances. To determine $(p, q)$, we adopt a general trading mechanism, denoted $\boldsymbol{\Gamma}$, assuming only mild conditions. First, trades depend only on the trading surpluses,

$$
\begin{aligned}
& S_{b}=u(q)+W_{b}\left(A_{b}-p\right)-W_{b}\left(A_{b}\right)=u(q)-\Lambda_{b} p, \\
& S_{s}=-c(q)+W_{s}\left(A_{s}+p\right)-W_{s}\left(A_{s}\right)=\Lambda_{s} p-c(q),
\end{aligned}
$$

which depend on the marginal utility of wealth $\left(\Lambda_{b}, \Lambda_{s}\right)$, but not on wealth $\left(A_{b}, A_{s}\right)$, by Lemma 2 . Second, $(p, q)$ depends on $L$ because of the constraint $p \leq L$.

\footnotetext{
${ }^{8}$ Versions of these results appear in Wong (2015), who also characterized the set of functions $U$ for which Assumption 1 holds. Without Assumption 1, the distribution of $\hat{m}$ in the DM is nondegenerate, which requires numerical methods (see, e.g., Chiu and Molico (2010, 2011)).
} 
Given $\left(\Lambda_{b}, \Lambda_{s}\right)$, define the unconstrained efficient quantity $q^{*}$ by

$$
u^{\prime}\left(q^{*}\right) / \Lambda_{b}=c^{\prime}\left(q^{*}\right) / \Lambda_{s},
$$

and let $p^{*}=\inf \left\{L: \Gamma_{q}(L)=q^{*}\right\}$ be the minimum payment required for a buyer to get $q^{*}$. To guarantee $q^{*} \in(0, \bar{q})$ is well defined, where $\bar{q}$ is a natural upper bound, assume DM gains from trade are positive but finite:

AsSUMPTION 2: $u^{\prime}(0) / \Lambda_{b}>c^{\prime}(0) / \Lambda_{s}$ and $\exists \bar{q}>0$ such that $u(\bar{q}) / \Lambda_{b}=$ $c(\bar{q}) / \Lambda_{s}$.

Then we focus on mechanisms of the form

$$
\Gamma_{p}(L)=\left\{\begin{array}{ll}
L & \text { if } L<p^{*}, \\
p^{*} & \text { otherwise, }
\end{array} \quad \text { and } \quad \Gamma_{q}(L)= \begin{cases}v^{-1}(L) & \text { if } L<p^{*}, \\
q^{*} & \text { otherwise }\end{cases}\right.
$$

where $v$ is some strictly increasing function with $v(0)=0$ and $v\left(q^{*}\right)=p^{*}$.

We now demonstrate that the specification in (9) is very general:

AsSUMPTION 3: The mechanism $\Gamma$ satisfies these axioms:

A1 (Feasibility): $\forall L, 0 \leq \Gamma_{p}(L) \leq L, 0 \leq \Gamma_{q}(L)$.

A2 (Individual Rationality): $\forall L, u \circ \Gamma_{q}(L) \geq \Lambda_{b} \Gamma_{p}(L)$ and $\Lambda_{s} \Gamma_{p}(L) \geq c \circ$ $\Gamma_{q}(L)$.

A3 (Monotonicity): $\Gamma_{p}\left(L_{2}\right)>\Gamma_{p}\left(L_{1}\right) \Leftrightarrow \Gamma_{q}\left(L_{2}\right)>\Gamma_{q}\left(L_{1}\right)$.

A4 (Bilateral Efficiency): $\forall L, \nexists\left(p^{\prime}, q^{\prime}\right)$ with $p^{\prime} \leq L$ such that $u\left(q^{\prime}\right)-\Lambda_{b} p^{\prime}>$ $u \circ \Gamma_{q}(L)-\Lambda_{b} \Gamma_{p}(L)$ and $\Lambda_{s} p^{\prime}-c(q)>\Lambda_{s} \Gamma_{p}(L)-c \circ \Gamma_{q}(L)$.

LeMma 3: Assumption 3 implies the mechanism $\boldsymbol{\Gamma}$ must take the form in (9).

See Gu and Wright (2015) for a proof. ${ }^{9}$ This class of mechanisms includes standard bargaining solutions, as discussed below. It also includes competitive price taking, which can be motivated by reinterpreting DM trade as multilateral, as in Rocheteau and Wright (2005), as well as creative mechanisms like the one designed by $\mathrm{Hu}$, Kennan, and Wallace (2009). In terms of content, (9) says this: a buyer gets the efficient quantity $q^{*}$ and pays some amount

\footnotetext{
${ }^{9}$ We mention a few details about Assumption 3. First, A3 does not say $S_{b}$ and $S_{s}$ are increasing in $L$, only that $p$ and $q$ move in the same direction as functions of $L$. Nash bargaining satisfies this, even though $S_{b}$ or $S_{s}$ can be decreasing in $L$, as discussed in a related context by Aruoba, Rocheteau, and Waller (2007). Also, A4 is actually not critical for the results below about credit (e.g., they hold for the inefficient monopsony mechanism considered in the working paper, $\mathrm{Gu}$, Mattesini, and Wright (2014)). In any case, it is an ex post condition saying parties in the DM do not want to deviate given $L$; it does not say the ex ante choice of $L$ in the CM is efficient. Also, in general, the mechanism $\Gamma$ depends on $\left(\Lambda_{b}, \Lambda_{s}\right)$ as well as $L$, but this is often suppressed in the notation. Finally, by assumption, $\boldsymbol{\Gamma}$ depends not on $(D, \phi m)$ but only $L=D+\phi m$, which is natural, since agents care only about the value and not the composition of the payment, but see Araujo and $\mathrm{Hu}(2014)$ and references therein for mechanisms that do depend on $(D, \phi m)$.
} 
$p^{*}=v\left(q^{*}\right)$, determined by the mechanism, as long as $p^{*} \leq L$; otherwise, he goes to the limit $p=L$, and gets $q=v^{-1}(L)<q^{*}$. Thus, $v^{-1}(L)$ is the quantity a constrained buyer gets, and $v(q)$ is how much he has to pay to get it. For convenience, it is also assumed that $v(q)$ is twice continuously differentiable almost everywhere.

Consider a seller. If he does not trade, he gets continuation value $W_{s}(0)$ (recall that sellers take no cash to the DM). If he trades, he gets this plus a surplus $\Lambda_{s} p-c(q)$, where $p=\Gamma_{p}(\bar{L})$ and $q=\Gamma_{q}(\bar{L})$ depend on the liquidity position of the buyer with whom he trades. For a buyer in the DM with real balances $\phi m$,

$$
V_{b}(\phi m)=W_{b}(\phi m-T)+\alpha\left[u(q)-\Lambda_{b} p\right],
$$

where $p=\Gamma_{p}(L)$ and $q=\Gamma_{q}(L)$ depend on his own liquidity. The Appendix verifies the following:

LEMMA 4: In stationary monetary equilibrium, buyers are constrained: $q<q^{*}$.

Constrained buyers exhaust their liquidity: $p=D+\phi m$. Substituting this into $V_{b}$, then $V_{b}$ into $W_{b}$, after simplifying we get

$$
\begin{aligned}
W_{b}(A)= & U_{0}^{b}+\Lambda_{b}(A-\beta T)+\beta W_{b}(0) \\
& +\beta\left\{-i \Lambda_{b} \phi_{+1} \hat{m}+\alpha\left[u\left(q_{+1}\right)-\Lambda_{b} v\left(q_{+1}\right)\right]\right\},
\end{aligned}
$$

with $i$ the nominal interest rate defined by the Fisher equation $1+i=(1+$ $\pi) / \beta .^{10}$ Clearly, it is equivalent for the monetary authority to set $i$ or $\pi$, so we take $i$ as the policy instrument, and note that the Friedman rule is the limit $i \rightarrow 0$. Then rewrite (11) as $W_{b}(A)=\Theta+\alpha \beta J\left(q_{+1} ; i\right)$, where $\Theta=\Lambda_{b} A+U_{0}^{b}-$ $\beta \Lambda_{b} T+\beta W_{b}(0)+\beta i \Lambda_{b} D$ is irrelevant for the choice of $\hat{m}$. Hence, the buyers' objective function can be written

$$
J\left(q_{+1} ; i\right)=u\left(q_{+1}\right)-(1+i / \alpha) \Lambda_{b} v\left(q_{+1}\right),
$$

which replaces the choice of $\hat{m}$ with the direct choice of $q_{+1}$.

We adopt the following assumption in the baseline model, and then discuss in Section 6 how it may or may not matter.

\footnotetext{
${ }^{10}$ For our purposes, the Fisher equation gives $i$ as the nominal return that makes agents indifferent to borrowing and lending across CM's, whether or not such trades occur in equilibrium. To derive (11), first write

$$
\begin{aligned}
& W_{b}(A) \\
& \quad=U_{0}^{b}+\Lambda_{b}(A-\phi \hat{m})+\beta\left\{W_{b}\left(\phi_{+1} \hat{m}-T\right)+\alpha\left[u\left(q_{+1}\right)-\Lambda_{b} v\left(q_{+1}\right)\right]\right\} \\
& \quad=U_{0}^{b}+\Lambda_{b}(A-\beta T)+\beta W_{b}(0)-\Lambda_{b} \phi \hat{m}+\beta\left\{\Lambda_{b} \phi_{+1} \hat{m}+\alpha\left[u\left(q_{+1}\right)-\Lambda_{b} v\left(q_{+1}\right)\right]\right\},
\end{aligned}
$$
}

and then use the Fisher equation. 
ASSUMPTION 4: $J(q ; i)$ is a single-peaked function of $q$.

It is known that Assumption 4 holds automatically for some mechanisms (e.g., Walrasian pricing or Kalai bargaining) but not others (e.g., Nash bargaining). While it simplifies some proofs, many results can be shown without it, although there is a complication in our application, as discussed below. To facilitate the presentation, for now, impose Assumption 4. Then, without loss of generality, impose $q \leq q^{*}$, and write the buyers' problem as

$$
q_{i}=\arg \max _{q} J(q ; i) \quad \text { s.t. } \quad q \in\left[0, q^{*}\right] .
$$

\section{EQUILIBRIUM}

In a monetary equilibrium, $\phi m>0$ and $v\left(q_{i}\right)>D$. This and Lemma 4 imply $v^{-1}(D)<q_{i}<q^{*}$, and since it is interior, $q_{i}$ satisfies the FOC

$$
e(q) \equiv u^{\prime}(q)-(1+i / \alpha) \Lambda_{b} v^{\prime}(q)=0 .
$$

Given a solution to $e\left(q_{i}\right)=0$, real balances are $\phi M=v\left(q_{i}\right)-D$, where, by market clearing, $m=M$. Hence, $\phi M>0$ iff $v\left(q_{i}\right)>D$.

DEFINITION 1: Given mechanism $\boldsymbol{\Gamma}$, debt limit $D$, and policy $i$, a (stationary) monetary equilibrium is a CM allocation $(x, \ell)$, DM outcome $(p, q)$, and real balances $\phi M$ such that: (i) $q$ solves (13), $p=v(q)$ and $\phi M=p-D>0$; (ii) $(x, \ell)$ solves (2) with $\hat{m}=0$ for sellers, $\hat{m}=M_{+1}$ for buyers, and $\int x=\omega \int \ell$.

DEFINITION 2: A nonmonetary equilibrium is similar except $\phi=0$.

As is standard in many, not all, related models, $(p, q)$ can be determined independently of $(x, \ell)$, so we can discuss some properties of the DM without reference to the $\mathrm{CM}$, which is convenient if not crucial for the results. The method is this: look for a solution $q_{i} \in\left[0, q^{*}\right]$ to (13); if $p_{i}=v\left(q_{i}\right)>D$, then $\phi M>0$ and monetary equilibrium exists; otherwise, $\phi=0$ and $q=$ $\min \left\{q^{*}, v^{-1}(D)\right\}$. To insure $q_{i}>0$, impose the following:

ASSUMPTION 5: $\exists q>0$ such that $\Lambda_{b} v(q)<u(q)$.

Notice this involves the mechanism $v(\cdot)$, while Assumption 2 only involves utility; it holds with bargaining, for example, whenever buyers have bargaining power $\theta>0$. Also, it implies $q_{0}=\arg \max _{q} J(q ; 0)>0$ when $i \rightarrow 0$, and so $q_{i}>0$ at least for $i$ not too big. However, $q_{i}>0$ does not mean we have a monetary equilibrium; that requires $q_{i}>v^{-1}(D)$. In any case, we have the next result: ${ }^{11}$

\footnotetext{
${ }^{11}$ Even without Assumption 4, Lemma 5 still holds for generic parameters, but it requires more of an argument (Gu and Wright (2015)).
} 


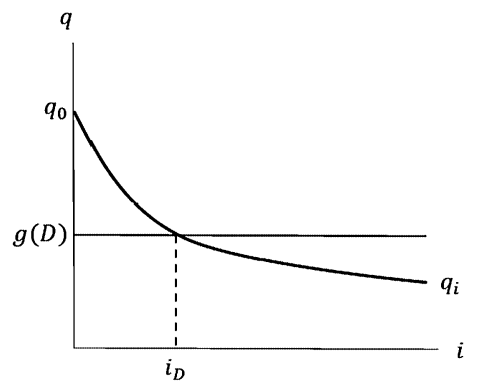

FIGURE 1.-DM quantity vs the nominal rate.

LEMMA 5: The solution to (13) is unique and $\partial q / \partial i<0$.

Figure 1 plots $q_{i}$ against $i$. It should be clear that $i=0$ is optimal, if it is feasible, and it implies $q_{0} \leq q^{*}$ (e.g., with Kalai bargaining, $q_{0}=q^{*} \forall \theta$, and with Nash bargaining, $q_{0}=q^{*}$ iff $\theta=1$ ). By Lemma 5, $q_{i}$ is unique and decreasing. Again, $\phi M>0$ iff $v\left(q_{i}\right)>D$. Given a $D$ such that $v^{-1}(D)<q_{0}$, as in Figure 1 , there is a unique $i_{D}>0$ such that monetary equilibrium exists iff $i<i_{D}$. Or, to state the results in terms of $D$, we have the following:

PROPOSITION 1: There are three cases:

1. if $v\left(q^{*}\right) \leq D$, there is no monetary equilibrium and there is a nonmonetary equilibrium with $q=q^{*}$;

2. if $v\left(q_{i}\right) \leq D<v\left(q^{*}\right)$, there is no monetary equilibrium and there is a nonmonetary equilibrium with $q \in\left[q_{i}, q^{*}\right)$;

3. if $D<v\left(q_{i}\right)$, there is a monetary equilibrium with $q=q_{i}$ plus a nonmonetary equilibrium with $q<q_{i}$.

The results follow directly from the above discussion; here we give more economic intuition. First suppose $D \geq v\left(q^{*}\right)$. Then buyers can get $q^{*}$ on credit, and if we try to construct a monetary equilibrium, we fail, since $\phi M=v\left(q_{i}\right)-D \leq$ $v\left(q^{*}\right)-D \leq 0$. Simply put, buyers unconstrained in terms of credit have no need for cash. Now suppose $v\left(q^{*}\right)>D \geq v\left(q_{i}\right)$. Then buyers can only get $q=v^{-1}(D)<q^{*}$ on credit, but if we try to construct a monetary equilibrium, we still fail, as $\phi M=v\left(q_{i}\right)-D \leq 0$. In this case, buyers are constrained in terms of credit, but not enough to make it worth carrying cash. Finally, suppose $v\left(q_{i}\right)>D$. Then $\phi M=v\left(q_{i}\right)-D>0$ and monetary equilibrium exists, because the constraint is tight enough to make cash worthwhile, given the cost of carrying it, as captured by the nominal rate.

Now notice something interesting: in monetary equilibrium, $q=q_{i}$ does not depend on $D$. This is because buyers acquire real balances up to the point where the marginal benefit equals $i$, as indicated by (14). Hence, $\phi M=v\left(q_{i}\right)-$ $D$ adjusts to guarantee that the liquidity provided by cash fills the gap between 
the $p$ required to get the desired $q_{i}$ and the debt limit. This is not to say an individual's debt limit is irrelevant: if we keep everyone else the same and lower $D$ for one agent, we can make him worse off; but if we lower $D$ for everyone, then $\phi$ adjusts to keep $L=D+\phi M$ and hence welfare exactly the same. In other words, if $D$ is low, money is essential (it improves welfare at least for some $i$ ), but in monetary equilibrium, credit is inessential and changes in credit conditions are neutral. Of course, if $v\left(q^{*}\right)>D>v\left(q_{i}\right)$, then $D$ matters, but then equilibrium must be nonmonetary.

This benchmark result is one of the main intended contributions of the paper. We formalize it as follows:

PROPOSITION 2: With exogenous policy and debt limits, in (stationary) monetary equilibrium, credit is used but is inessential, and changes in $D$ are neutral given $i$.

To be clear, the result says that changes in $D$ are neutral given $i$ is fixed. One can imagine monetary policies violating this, for example, adjusting $i$ automatically to maintain a target $\phi$. If a change in $D$ were to trigger an automatic response in $i$, it would have real effects, but these would clearly be due to the difference in policy and not the difference in credit conditions. Also, we are assuming buyers know of any changes in $D$ when they choose $\hat{m}$ in the CM. If a $D$ change catches them by surprise, after the DM closes, there can be a real effect, but it would last only one period.

The neutrality of $D$ in monetary equilibrium may be surprising, since one might have thought that a higher debt limit would allow buyers to economize on cash balances while staying equally liquid. This seems especially desirable when DM trade is random, because then buyers sometimes acquire money they do not use. However, increases in debt limits are exactly offset by decreases in the value of currency, so that there is complete crowding out of $\phi M$ by $D$. Or, to say it in reverse, while one can argue using partial equilibrium reasoning that it is bad to tighten credit, in general equilibrium, currency becomes more valuable when debt limits fall. To the extent that money can substitute for credit, debt limits matter less than one would conclude based on nonmonetary models.

\section{ENDOGENOUS POLICY AND DEBT LIMITS}

To have money and credit both useful, neither should be perfect: if debt were unconstrained, money is inessential; and if monetary policy were unconstrained, by which we mean $i$ can be set low enough, credit can be inessential. Even without credit, for some mechanisms (e.g., Walrasian pricing or Kalai bargaining) we get $q^{*}$ iff $i=0$, while for others (e.g., the ones in $\mathrm{Hu}$, Kennan, and Wallace (2009) or Gu and Wright (2015)) we can get $q^{*}$ for $i>0$ but only if $i$ is not too high. Hence, it is of interest to establish an endogenous lower 
bound on the nominal rate, to give credit a chance, just like establishing an endogenous upper bound on debt gives money a chance. To this end, we now allow agents to renege on debt and taxes. There is some monitoring, so renegers may be punished, but this occurs with probability less than 1 . Imperfect tax monitoring bounds $i$ because $i<r$ requires deflation, which means reducing $M$, which requires $T>0$. This is nice, we think, because the same friction that hinders credit potentially hinders monetary exchange by precluding low $i$, which seems like a reasonable way to give both money and credit a chance.

Specifically, we check whether buyers honor their private (debt) and public (tax) obligations with probabilities $\mu_{D}$ and $\mu_{T} .{ }^{12}$ In terms of timing, they simultaneously choose one of the following options: pay both $d$ and $T$; pay only $d$; pay only $T$; or pay neither. Then they are randomly monitored by the credit and fiscal authorities. If a buyer pays $d$ and $T$, or reneges on either one, but is not caught because he was not monitored, he chooses $(x, \ell, \hat{m})$ as before. As a benchmark, anyone caught reneging on $d$ or $T$ is banished to autarky, but the Appendix considers the case where they can continue in the DM only using cash. In autarky, agents produce $x$ for themselves and pay no more taxes, but we let them spend any cash on hand in the period they are caught. Since anyone excluded from the DM in the future chooses $\hat{m}=0$, the autarky payoff is $W(\phi m)=\Lambda_{b} \phi m+U_{0}(1+r) / r$.

To ensure that agents pay their taxes and debts, we need to impose the following incentive constraints:

$$
\begin{aligned}
& W_{b}(\phi m-d-T) \geq\left(1-\mu_{T}\right) W_{b}(\phi m-d)+\mu_{T} \underline{\underline{W}}(\phi m), \\
& W_{b}(\phi m-d-T) \geq\left(1-\mu_{D}\right) W_{b}(\phi m-T)+\mu_{D} \underline{\underline{W}}(\phi m), \\
& W_{b}(\phi m-d-T) \\
& \quad \geq\left(1-\mu_{D}\right)\left(1-\mu_{T}\right) W_{b}(\phi m)+\left(\mu_{D}+\mu_{T}-\mu_{D} \mu_{T}\right) \underline{W}(\phi m) .
\end{aligned}
$$

The LHS in each case is the equilibrium payoff; (15) says this beats defaulting on taxes; (16) say this beats defaulting on debts; and (17) says this beats defaulting on both. Since $W$ is linear, (15) and (16) reduce to

$$
\begin{aligned}
T \Lambda_{b} & \leq \mu_{T}\left[W_{b}(\phi m-d)-\underline{W}(\phi m)\right], \\
d \Lambda_{b} & \leq \mu_{D}\left[W_{b}(\phi m-T)-\underline{W}(\phi m)\right] .
\end{aligned}
$$

\footnotetext{
${ }^{12}$ As we said above, this is based on a formulation that proved useful in Gu et al. (2013a, 2013b), but there are other ways to proceed. Different versions of imperfect monitoring or record keeping in related models include Kocherlakota and Wallace (1998), where deviations are observed with a lag; Cavalcanti and Wallace (1999), where some agents are monitored while others are not; Sanches and Williamson (2010), where some meetings are monitored and other not; and Amendola and Ferraris (2013), where information gets lost over time.
} 
We call (18) the tax payment constraint and (19) the debt payment constraint. If they both hold, then (17) is redundant. Also, $T \leq 0$ implies (18) is redundant (no one walks away from a negative tax liability-that is, from a transfer).

Inserting $W_{b}$ and $\underline{W}$ into (18) and using $v(q)=\phi m+d$, we get

$$
T \leq \frac{\mu_{T}}{1-\mu_{T}} \frac{\alpha}{r}\left[\frac{u(q)}{\Lambda_{b}}-\left(1+\frac{r}{\alpha}\right) v(q)\right] .
$$

By $T=-\pi \phi M$ and the Fisher equation, the tax payment constraint thus reduces to

$$
\frac{r-i}{1+r} \phi M \leq \frac{\mu_{T}}{1-\mu_{T}} \frac{\alpha}{r}\left[\frac{u(q)}{\Lambda_{b}}-\left(1+\frac{r}{\alpha}\right) v(q)\right] .
$$

If $i \geq r$, this holds trivially; otherwise, it puts a lower bound on $i$.

DEFINITION 3: Policy $i$ is feasible if a monetary equilibrium exists where (20) holds.

Similarly, the debt payment constraint reduces to

$$
d \leq \frac{\mu_{D}}{r}\left\{\alpha\left[u(q) / \Lambda_{b}-v(q)\right]-r \phi M\right\} .
$$

We now endogenize $D$ by adapting the method in Alvarez and Jermann (2000) to a monetary economy. First pick an arbitrary $D$. Generally, the equilibrium and hence the RHS of (21) depend on D. From Proposition 1, this can be written

$$
\Phi(D) \equiv\left\{\begin{aligned}
& \xi\left[u\left(q_{i}\right) / \Lambda_{b}-(1+r / \alpha) v\left(q_{i}\right)\right]+\mu_{D} D \\
& \text { if } D<v\left(q_{i}\right), \\
& \xi\left[u \circ v^{-1}(D) / \Lambda_{b}-D\right] \\
& \text { if } v\left(q_{i}\right) \leq D<v\left(q^{*}\right), \\
& \xi\left[u\left(q^{*}\right) / \Lambda_{b}-v\left(q^{*}\right)\right] \\
& \text { if } v\left(q^{*}\right)<D,
\end{aligned}\right.
$$

where $\xi \equiv \mu_{D} \alpha / r$. Each branch corresponds to one of the three cases in Proposition 1 , assuming we select the monetary equilibrium when it exists, in the branch where $D<v\left(q_{i}\right)$. See Figure 2. ${ }^{13}$

\footnotetext{
${ }^{13}$ The dashed curve is drawn selecting nonmonetary equilibrium instead. We focus on the solid curve, of course, because we are interested in monetary equilibrium and money's interaction with credit. See Gu et al. (2013b), Carapella and Williamson (2014), and Bethune, Rocheteau, and $\mathrm{Hu}$ (2014) for recent analyses of endogenous debt limits in nonmonetary models, including nonstationary and asymmetric outcomes, and cases with default in equilibrium.
} 


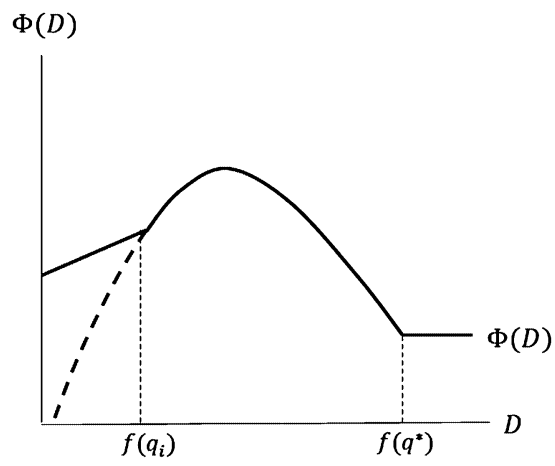

FIGURE 2.-The correspondence $(D)$.

If we pick $D$ exogenously, agents are willing to honor obligation $d$ iff $d \leq$ $\Phi(D)$, because $\Phi(D)$ is what they stand to lose if they renege. Hence we have the following:

DEFINITION 4: An endogenous debt limit is a nonnegative fixed point $\hat{D}=$ $\Phi(\hat{D})$.

Notice $\Phi$ is continuous, $\Phi(D)=\Phi^{*}>0$ is constant for $D \geq v\left(q^{*}\right)$, and we claim $\Phi(0)>0$ (see footnote 14 ). Hence a fixed point $\hat{D}=\Phi(\hat{D})$ always exists, and it cannot be $\hat{D}=0$.

Moreover, a fixed point $\hat{D}$ may or may not be consistent with monetary equilibrium-this requires $\hat{D}<v\left(q_{i}\right)$, meaning that we are on the first branch of $\Phi(D)$. Notice the first branch is actually linear, with slope $\mu_{D}$, and therefore there can be at most one monetary fixed point, but we cannot rule out the coexistence of monetary and nonmonetary fixed points. In any case, for an endogenous debt limit to be consistent with monetary equilibrium, the fixed point must be on the linear branch of $\Phi(D)$, in which case we can solve for it explicitly. Before pursuing this, we catalogue the possible outcomes as follows: ${ }^{14}$

\footnotetext{
${ }^{14}$ To verify the claim $\Phi(0)>0$, it can be checked that, for $i \geq r$, we have $\Phi(0)>\xi J\left(q_{i} ; i\right)>0$, and for $i<r$, we have $\Phi(D)>0 \forall D>0$ if $i$ satisfies (20). Hence, $\Phi(0)>0$ for feasible policies. In terms of substance, given $\Phi(0)>0$ and given we select the monetary equilibrium for low $D$, $D=0$ is not a fixed point, while it would be if we were to select the nonmonetary equilibrium (see the dashed curve in Figure 2). Thus, selecting monetary equilibrium at low $D$ precludes a degenerate endogenous debt limit $D=0$, and so one might say money is good for credit in this environment, even though they are substitutes in payments. This is different from models where money is bad for credit (e.g., Aiyagari and Williamson (1999) or Berentsen, Camera, and Waller (2007)), and obtains because the punishment is autarky, not monetary trade (again, that other case is covered in the Appendix).
} 
Proposition 3: Given a feasible policy $i, \exists \hat{D}=\Phi(\hat{D})>0$. There are three cases:

1. if $v\left(q^{*}\right) \leq \hat{D}$, there is no monetary equilibrium and there is a nonmonetary equilibrium with $q=q^{*}$;

2. if $v\left(q_{i}\right) \leq \hat{D}<v\left(q^{*}\right)$, there is no monetary equilibrium and there is a nonmonetary equilibrium with $q \in\left[q_{i}, q^{*}\right)$;

3. if $\hat{D}<v\left(q_{i}\right)$, there is a monetary equilibrium with $q=q_{i}$.

We now combine the endogenous debt limit with the limit on feasible policy. First, in monetary equilibrium, we can solve explicitly for

$$
\hat{D}_{i}=\frac{\mu_{D}}{1-\mu_{D}} \frac{\alpha}{r}\left[u\left(q_{i}\right) / \Lambda_{b}-(1+r / \alpha) v\left(q_{i}\right)\right]
$$

where we now indicate that $\hat{D}_{i}$ depends on $i$. Monetary equilibrium requires: (i) $\hat{D}<v\left(q_{i}\right)$, which says the debt limit is tight enough for money to be valued; and (ii) condition (20) holds, which says agents are willing to pay taxes. From (23), $\hat{D}<v\left(q_{i}\right)$ iff $H\left(q_{i}\right)<0$, where $H(q) \equiv u(q) / \Lambda_{b}-\left(1+r / \alpha \mu_{D}\right) v(q)$. For $i \geq r,(20)$ always holds, while for $i<r$, a calculation implies it holds iff $K\left(q_{i} ; i\right) \geq 0$, where

$$
\begin{aligned}
& K(q ; i) \\
& \quad \equiv \frac{u(q)}{\Lambda_{b}}-\left[1+\frac{r}{\alpha} \frac{\mu_{T}\left(1-\mu_{D}\right)(1+r)+\left(1-\mu_{T}\right)(r-i)}{\mu_{T}\left(1-\mu_{D}\right)(1+r)+\mu_{D}\left(1-\mu_{T}\right)(r-i)}\right] v(q) .
\end{aligned}
$$

Hence, for $i<r$, monetary equilibrium requires $H\left(q_{i}\right)<0 \leq K\left(q_{i} ; i\right)$.

We formalize these results as follows:

PROPOSITION 4: Given $i>0$, consider trying to construct a monetary equilibrium with $q_{i}$ solving (14) and an endogenous debt limit $\hat{D}_{i}$ given by (23). Then we have:

1. if $H\left(q_{i}\right) \geq 0$, then $i$ is not consistent with monetary equilibrium;

2. if $H\left(q_{i}\right)<0$, then monetary equilibrium exists for $i$ iff (a) $i \geq r$ or (b) $i<r$ and $K\left(q_{i} ; i\right) \geq 0$.

In particular, a direct corollary of Proposition 4 is a generalization of Kocherlakota's (1998) result that money cannot be essential if $\mu_{D}=1$. $^{15}$

\footnotetext{
${ }^{15}$ To verify this, simply insert $\mu_{D}=1$ into the conditions for monetary equilibrium to exist. We do not quite have a symmetric result saying that credit cannot be essential if $\mu_{T}=1$. It is true that tax payment constraint is more likely to hold for big $\mu_{T}$, but this does not mean $i=0$ is feasible at $\mu_{T}=1$, which is what it would take to say credit is inessential. In fact, a calculation shows $i=0$ is feasible if $(1+r / \alpha) v\left(q_{0}\right) \leq u\left(q_{0}\right)<\left(1+r / \alpha \mu_{D}\right) v\left(q_{0}\right)$.
} 

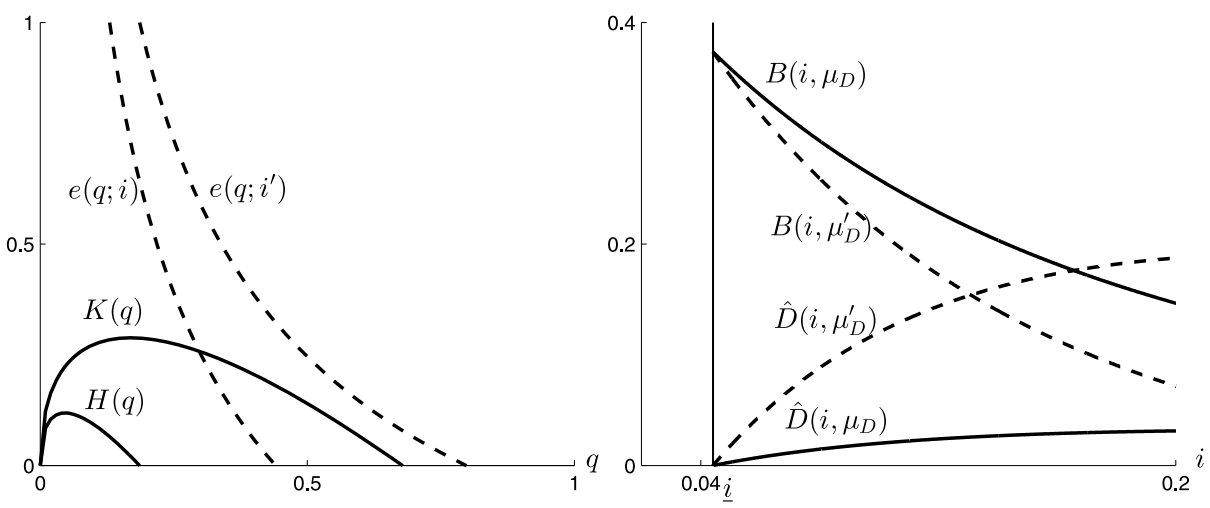

FiguRE 3.-Endogenous debt and deflation limits.

\section{Proposition 5: With $\mu_{D}=1$ and endogenous $D, \nexists$ monetary equilibrium.}

It is hard to characterize in general the set of feasible $i$ 's, and it may not even be a connected set, given the nonlinearity of the model. However, we can easily describe monetary equilibria when they exist: $q_{i}$ satisfies (14) and $\hat{D}$ in terms of $q_{i}$ is given by (23). After some algebra,

$$
\phi_{i} M=v\left(q_{i}\right)-\hat{D}_{i}=\frac{\alpha u\left(q_{i}\right) / \Lambda_{b}-\left(\alpha+r \mu_{D}\right) v\left(q_{i}\right)}{r\left(1-\mu_{D}\right)},
$$

and one can check if $i$ is a feasible policy. Figure 3 shows some examples. ${ }^{16}$ The left panel depicts $H(q), K(q)$, and $e(q)$, where $e(q)=0$ gives a candidate equilibrium. For $i=0.04$, the candidate $q$ satisfies $H(q)<0<K(q)$, so it is a monetary equilibrium. For $i^{\prime}=0.01$, the candidate violates $0<K(q)$, so it is not an equilibrium, in this case because people would not pay $T$. The right panel shows the effect of $i$ on $\hat{D}$ and real balances $B$ (scaled by output to be consistent with standard notions of money demand).

A feasible policy in this example means $i$ is not too high, so money is a viable alternative to credit, nor too low, so taxes are incentive compatible. Notice also that the money demand curve endogenously shifts in response to, for example, changes in $\mu_{D}$, naturally. But for present purposes, the key point is this: As with exogenous policy and debt limits, in monetary equilibrium, credit is inessential and changes in debt limits are neutral, because real balances adjust endogenously so that total liquidity is the same. Of course, we cannot change $D$ directly when it is endogenous; by credit conditions, we now mean changes in

\footnotetext{
${ }^{16}$ The left panel uses Kalai bargaining with $\theta=0.85, u(q)=2 \sqrt{q}, c(q)=q, \Lambda_{j}=\omega=1, r=$ $\alpha=0.1, \mu_{D}=0.5$, and $\mu_{T}=1$. In the right panel, $U^{j}(x, \ell)=2 \log (x)+\ell, r=\alpha=0.25$, and $\mu_{D}$ is either 0.4 or 0.1 .
} 
the parameters affecting $\hat{D}$, like $\mu_{D}$. Such changes are neutral. However, there is a small caveat. As before, when we say $D$ is neutral, we mean it has no real effect given $i$. When parameters change, however, it may now be possible, or even necessary, to change $i$ since the set of feasible policies can change. That would not be neutral, but it is the change in $i$ that matters, not the change in $D$. We formalize this as follows:

PROPOSITION 6: With endogenous policy and debt limits, in (stationary) monetary equilibrium, credit is used but is inessential, and changes in $D$ are neutral given $i$. However, it may be feasible, or even necessary, to change $i$ when parameters change.

\section{EXTENSIONS}

We now consider robustness, focusing mainly on exogenous $D$ and $T$ (but see footnote 19).

\subsection{Costly Credit}

As in Bethune, Choi, and Wright (2015) and references therein, suppose buyers can go into debt beyond $D$ if they pay cost $\eta(p-D-\phi m)$, where $\eta(0)=\eta^{\prime}(0)=0$, and $\eta^{\prime}(q), \eta^{\prime \prime}(q)>0 \forall q>0$. A buyer's DM surplus is now $S_{b}=u(q)-p \Lambda_{b}-\eta(p-L) \mathbb{I}\{p>L\}$, where $\mathbb{I}$ is an indicator function, while the seller's surplus $S_{s}=\Lambda_{s} p-c(q)$ is as before. ${ }^{17}$ The trading mechanism must yield outcomes in the bilateral core, constructed as follows. First, solve $\max _{p, q} S_{b}$ s.t. $S_{s} \geq \bar{S}_{s}$ for a given $\bar{S}_{s}$. The FOC implies

$$
u^{\prime}(q)=\left\{\Lambda_{b}+\eta^{\prime}\left[\frac{\bar{S}_{s}+c(q)}{\Lambda_{s}}-L\right]\right\} \frac{c^{\prime}(q)}{\Lambda_{s}}
$$

if $\Lambda_{s} L<\bar{S}_{s}+c\left(q^{*}\right)$, and $q=q^{*}$ otherwise. The core is

$$
\mathcal{C} \equiv\left\{(p, q) \mid q \text { solves (25), } p=\left[c(q)+S_{s}\right] / \Lambda_{s}, S_{s} \geq 0 \text {, and } S_{b} \geq 0\right\} .
$$

We need to amend Assumption 3 slightly. Since $p>L$ is now possible, we drop the constraints $\Gamma_{p} \leq L$ in A1 and $p^{\prime} \leq L$ in A4. Any mechanism satisfying these axioms still has $p=p^{*}$ and $q=q^{*}$ if $L>p^{*}$, but we can have $p>L$ and $q=v^{-1}(p)$, where $v^{\prime}(q)>0$, if $L<p^{*}$ (see Gu and Wright (2015) for details). Then rewrite (25) as

$$
u^{\prime}(q)=\left\{\Lambda_{b}+\eta^{\prime}[v(q)-L]\right\} c^{\prime}(q) / \Lambda_{s},
$$

\footnotetext{
${ }^{17}$ In fact, it does not matter who pays the cost, just like it does not matter whether buyers or sellers pay sales taxes in elementary public finance.
} 
which implies $\partial q / \partial L>0$. Given this, write (26) as $L=\zeta(q)$, where $\zeta$ is increasing. By A3, $p$ is also increasing in $L$. The key point is that trade is not constrained by $p \leq L$, because this constraint can now be relaxed at a cost.

When $D \geq p^{*}$, there is no monetary equilibrium. When $D<p^{*}$, there are two cases: (i) $\phi m=0$, where payments are financed exclusively by credit, some of which involves the transaction cost $\eta$; or (ii) $\phi m>0$, where money is also used. In the first case, $q$ is solved from (26) by setting $L=D$. Denote the solution by $\tilde{q}_{D}$. In the second case, the DM value function is

$$
V(\phi m)=W(\phi m)+\alpha\left\{u(q)-\Lambda_{b} v(q)-\eta[v(q)-L]\right\},
$$

and the buyers' problem can be written

$$
\tilde{J}(q ; i)=u(q)-\eta[v(q)-\zeta(q)]-\Lambda_{b}[v(q)+i \zeta(q) / \alpha] .
$$

Let us impose Assumption 4 on $\tilde{J}(q ; i)$, so it is single peaked, and let

$$
\tilde{q}_{i}=\arg \max \tilde{J}(q ; i) \quad \text { s.t. } \quad q \in\left[0, q^{*}\right] .
$$

There is a monetary equilibrium iff $\tilde{q}_{i}>\tilde{q}_{D}$. From (27), $\tilde{q}_{i}$ does not depend on $D$, although it does depend on $\eta$, since the use of costly credit entails resources. Still, changes in $D$ are neutral in monetary equilibrium, exactly as in the baseline model.

\subsection{Relaxing Assumption 4}

We now return to the case where debt limits are fixed (cannot be relaxed at cost $\eta)$ and consider a particular instance where $J(q ; i)$ is not single peaked. Gu and Wright (2015) showed $q_{i}=\arg \max _{q \in\left[0, q^{*}\right]} J(q ; i)$ is unique for generic parameters, even if $J(q ; i)$ is not single peaked, but in the present context, with both money and credit, $q_{i}$ may not constitute a monetary equilibrium. Consider Figure 4, with local maximizers at $q_{i}$ and $q_{i}^{\prime}$. Buyers get at a minimum, without using cash, $q_{D}=v^{-1}(D)$. Since $q_{i}<q_{D}<q_{i}^{\prime}, q_{i}$ does not constitute a monetary equilibrium while $q_{i}^{\prime}$ does. Although $J\left(q_{i} ; i\right)>J\left(q_{i}^{\prime} ; i\right)$, it is not feasible for buyers to get $q_{i}$ because, given $D$, the mechanism allocates them at least $q_{D}$.

This implies that buyers might be better off with a lower $D$-which is no surprise, since (as discussed at length in Gu et al. (2013b)) this can happen naturally with Walrasian pricing and with Nash bargaining. In this example, if the debt limit were to drop below $v^{-1}\left(q_{i}\right)$, there would emerge a monetary equilibrium at $q_{i}$. Therefore, changes in $D$ are not neutral, because they may generate a discrete change in the nature of equilibrium: as it rises from $D<$ $v^{-1}\left(q_{i}\right)$ to $D>v^{-1}\left(q_{i}\right), q$ jumps from $q_{i}$ to $q_{i}^{\prime}$. This is a legitimate exception, although $J(q ; i)$ was single peaked in any example we tried. Moreover, this kind of effect is not likely to show up in conventional macro models, which only consider Walrasian pricing, and that tends to make $J(q ; i)$ single peaked. 


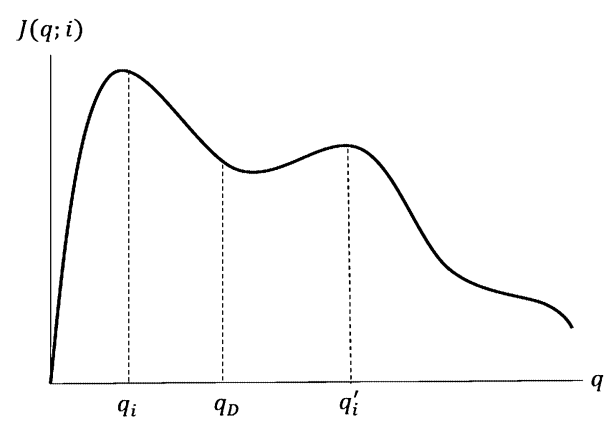

FIGURE 4.- $J$ is not single peaked.

\subsection{Heterogeneity}

We now consider heterogeneous preferences, which implies the terms of trade can differ across meetings. One might expect, for example, that people use money for small and credit for big purchases, as in some earlier literature (see Nosal and Rocheteau (2011, Chapter 8)). Could money and credit both be essential if $q$ is sometimes small and sometimes large? More generally, what might heterogeneity in DM meetings do to the results?

First, suppose $D$ is constant across matches. Let $\mathcal{U}_{j}^{b}=u_{j}(q)+U_{j}^{b}(x, 1-\ell)$ be the preferences for a type- $j$ buyer and $\mathcal{U}_{h}^{s}=-c_{h}(q)+U_{h}^{s}(x, 1-\ell)$ for a type- $h$ seller. Let $F(j)$ be the distribution of buyer types, and $G(h \mid j)$ the distribution of sellers a type- $j$ buyer might encounter in the DM. Also, suppose for now that buyers, when they choose $\hat{m}$, do not know which type of seller they will meet in the DM. Let $\mathcal{C}_{j}\left(L_{j}\right)=\left\{h: L_{j}<v_{j, h}\left(q_{j, h}^{*}\right)\right\}$, where $q_{j, h}^{*}$ solves $u_{j}^{\prime}(q) / \Lambda_{j}=$ $c_{h}^{\prime}(q) / \Lambda_{h}$, be the set of sellers with which the buyer is constrained. Here it is more natural to frame buyers' choice as $L$, rather than $q$, and write their objective function as

$$
J\left(L_{j} ; i\right)=\int_{\mathcal{C}_{j}\left(L_{j}\right)}\left[u_{j} \circ v_{j, h}^{-1}\left(L_{j}\right)-\Lambda_{j} L_{j}\right] d G_{j}(h \mid j)-\Lambda_{j} L_{j} i / \alpha .
$$

As long as $L_{j}>D$ — that is, as long as $\hat{m}_{j}>0$ —changes in $D$ do not affect $L_{j}$ and hence are still neutral.

Now suppose a buyer knows the type of seller he will meet in the next DM while still in the CM. Suppose provisionally that all buyers bring $\hat{m}_{j, h}>0$. Then the DM quantity $q_{j, h}^{i}$ solves

$$
u_{j}^{\prime}(q)=(1+i / \alpha) v_{j, h}^{\prime}(q) \Lambda_{j},
$$

which again does not depend on $D$. Again, changes in $D$ are neutral when every buyer chooses $\hat{m}>0$. However, the result may not hold if some buyers choose $\hat{m}=0$ even though they get $q<q^{*}$. In this case, changes in $D$ matter. 
This should be no surprise. With homogeneity, clearly $D$ matters when $q=$ $v^{-1}(D)<q^{*}$, but this is a nonmonetary equilibrium. With heterogeneity, for buyers who choose $\hat{m}=0$ even though $q=v^{-1}(D)<q^{*}$, the situation is similar, but the equilibrium can still be monetary if other buyers choose $\hat{m}>0$. What matters for nonneutrality, therefore, is not heterogeneity per se, but having some agents choose $\hat{m}=0$ even though $q<q^{*}$. The benchmark results hold if, for all buyers, either $\hat{m}>0$ or $D \geq v\left(q^{*}\right)$.

Another way to make credit matter is to let $D$ vary across sellers, say because they have different $\mu_{D}$. Denote the distribution across DM meetings by $\tilde{F}(D)$ and assume buyers in the CM do not know who they will meet in the DM, so all choose the same $\hat{m}$. Then $q=q^{*}$ if $\phi m+D \geq v\left(q^{*}\right)$ and $q=v^{-1}(\phi m+D)$ otherwise, so there is a $D^{*}$ below which buyers are constrained. If we increase the average $D$, or otherwise change $F(D)$, it affects the set of meetings that are constrained. As with the other examples, this shows how certain, but not all, types of heterogeneity can make credit conditions matter. But note again that this effect would not show up in conventional credit models, where trade is not bilateral, and monitoring, let alone heterogeneous monitoring, is not incorporated explicitly. Therefore, it is less than obvious that credit would matter in those conventional models if currency is introduced. ${ }^{18}$

\subsection{Real Pledgeable Assets}

Now consider a real asset $a$, in fixed supply normalized to 1 , that has price $\psi$ and pays dividend $\gamma>0$ in numeraire in the CM. To avoid a minor technicality discussed in Geromichalos, Licari, and Lledo (2007) and Lagos and Rocheteau (2008), assume in monetary equilibrium $q_{0}=q^{*}$ at $i=0$, as is always true for, for example, Walrasian pricing or Kalai bargaining. Also, here we start without, and then reintroduce, fiat money. The CM budget constraint is $x=\omega \ell+\gamma a+\psi(a-\hat{a})-d$. In the DM, $v(q) \leq D+\chi(\psi+\gamma) \hat{a}$, where $\chi \leq 1$ denotes the fraction of assets that can be used in DM trade. As in Kiyotaki and Moore (1997), think of $\chi$ as the fraction of $a$ that is pledgeable as collateral (one interpretation is that if a debtor defaults, off the equilibrium path, we can punish him by seizing a fraction $\chi$ of his assets while he absconds with the rest). Hence, there is both unsecured credit, limited by $D$, and secured credit, limited by $\chi(\psi+\gamma) \hat{a}$.

The DM constraint binds iff $\chi \gamma$ is low (Geromichalos, Licari, and Lledo (2007), Lester, Postlewaite, and Wright (2012)). When it does not bind, $q=q^{*}$

\footnotetext{
${ }^{18}$ Some other New Monetarist models derive related results, including Sanches and Williamson (2010), Berentsen and Waller (2011), Lotz and Zhang (2013), Gomis-Porqueras and Sanches (2013), and Araujo and $\mathrm{Hu}$ (2014). While it is interesting to see how credit may matter with certain types of heterogeneity, it is also important to know that credit does not matter with other types of heterogeneity.
} 
and the asset price is its fundamental value $\psi=\psi^{*} \equiv \gamma / r$. When it binds, the Euler equation is

$$
\psi=\beta\left(\psi_{+1}+\gamma\right)\left[1+\alpha \chi \frac{u^{\prime}(q)-\Lambda_{b} v^{\prime}(q)}{\Lambda_{b} v^{\prime}(q)}\right]
$$

In stationary equilibrium, this can be rearranged as

$$
u^{\prime}(q)=\left[1+\frac{r \psi-\gamma}{\alpha \chi(\psi+\gamma)}\right] \Lambda_{b} v^{\prime}(q) .
$$

There is a unique equilibrium $(q, \psi) \in\left(0, q^{*}\right) \times\left(\psi^{*}, \infty\right)$ solving (30) and $v(q)=D+\chi(\psi+\gamma)$. In this case, raising $D$ or $\chi$ increases $q$, so credit conditions are not neutral. ${ }^{19}$

However, this does not overturn the result that credit is irrelevant in monetary economies, because the above analysis concerns a nonmonetary outcome. Bringing cash back, the Euler equations for $\hat{m}$ and $\hat{a}$ are

$$
\begin{aligned}
& \phi=\beta \phi_{+1}\left[1+\alpha \frac{u^{\prime}(q)-\Lambda_{b} v^{\prime}(q)}{\Lambda_{b} v^{\prime}(q)}\right], \\
& \psi=\beta\left(\psi_{+1}+\gamma\right)\left[1+\alpha \chi \frac{u^{\prime}(q)-\Lambda_{b} v^{\prime}(q)}{\Lambda_{b} v^{\prime}(q)}\right] .
\end{aligned}
$$

In a stationary monetary equilibrium, (31) reduces to $u^{\prime}(q)=(1+i / \alpha) \Lambda_{b} v^{\prime}(q)$, identical to the baseline model. Hence, as long as money is valued, $q$ does not depend on $D$ or $\chi$, so adding Kiyotaki-Moore credit with real assets in fixed supply does not affect the results. ${ }^{20}$

\subsection{Reproducible Capital}

Consider now introducing capital $K$, with $\rho$ and $\delta$ the rental and depreciation rates. The (constant returns) production function in the $\mathrm{CM}$ is $f(N, K)$,

${ }^{19}$ To see how one endogenizes $D$ with a real asset, consider the analog to (22):

$$
\Phi(D)=\left\{\begin{array}{c}
\xi J \circ q(D) / \Lambda_{b}+\frac{\mu_{D}}{r} \frac{(1+r-\chi) \psi(D)-\chi \gamma}{\chi[\psi(D)+\gamma]} D \\
\quad \text { if } D<v\left(q^{*}\right)-\chi \gamma(1+r) / r, \\
\xi\left[u\left(q^{*}\right) / \Lambda_{b}-v(q)\right] \\
\text { if } D \geq v\left(q^{*}\right)-\chi \gamma(1+r) / r .
\end{array}\right.
$$

Now $\Phi(D)$ only has two branches; the middle branch in the benchmark model, where $D$ is not big enough to get $q^{*}$ but the asset is still not valued, only occurs with fiat money.

${ }^{20}$ Note $\chi$ does affect the asset price $\psi=\gamma(1+\chi i) /(r-\chi i)$, but that is irrelevant for the allocation, as it simply crowds out real balances to leave $L$ the same. Moreover, it was already true that $D$ affects asset prices in the baseline model, where it affects $\phi$. 
where $N$ is total employment. Profit maximization implies $\omega=f_{1}(N, K)$ and $\rho=f_{2}(N, K)$. We focus here on monetary equilibria, which exist under natural parameter conditions (see, e.g., Venkateswaran and Wright (2013)). Then the CM budget equation is $x+\phi \hat{m}+\hat{k}=A+\omega \ell$, where $A=\phi m+(\rho+1-\delta) k-$ $d-T$ and $k$ is individual, while $K$ is aggregate capital. The DM constraint is $p \leq D+\phi m+\chi(\rho+1-\delta) k$, again including a pledgeability parameter $\chi$. The Euler equations for $\hat{m}$ and $\hat{k}$ are

$$
\begin{aligned}
& \Lambda_{b} \phi=\beta \Lambda_{b,+1} \phi_{+1}\left[1+\alpha \frac{u^{\prime}\left(q_{+1}\right)-\Lambda_{b,+1} v^{\prime}\left(q_{+1}\right)}{\Lambda_{b,+1} v^{\prime}\left(q_{+1}\right)}\right], \\
& \Lambda_{b}=\beta \Lambda_{b,+1}\left(\rho_{+1}+1-\delta\right)\left[1+\alpha \chi \frac{u^{\prime}\left(q_{+1}\right)-\Lambda_{b,+1} v^{\prime}\left(q_{+1}\right)}{\Lambda_{b,+1} v^{\prime}\left(q_{+1}\right)}\right] .
\end{aligned}
$$

Even in stationary equilibrium, outside of steady state, $K$ and other variables vary over time. In particular, $\Lambda_{j}$ can depend on $\omega$ and hence on $K$, which may or may not imply that $q$ depends on $K$.

It is instructive to consider two examples, with different $\mathrm{CM}$ utility functions. For the first, suppose $U^{j}(x, 1-\ell)=\tilde{U}(x)-\ell$ is quasi-linear, which implies $\Lambda_{j}=\tilde{U}^{\prime}(x)=1 / \omega$. Also assume Kalai bargaining, $v(q)=[\theta c(q)+(1-$ $\theta) u(q)] \omega$. Given $K_{0}$, equilibrium consists of paths for $\left(q, x, K_{+1}, N\right)$ satisfying

$$
\begin{aligned}
& u^{\prime}(q)=(1+i / \alpha)\left[\theta c^{\prime}(q)+(1-\theta) u^{\prime}(q)\right], \\
& 1=f_{1}(N, K) \tilde{U}^{\prime}(x), \\
& \tilde{U}^{\prime}(x)=\beta \tilde{U}^{\prime}\left(x_{+1}\right)\left[f_{2}\left(N_{+1}, K_{+1}\right)+1-\delta\right](1+\chi i), \\
& 2 x=f(N, K)+(1-\delta) K-K_{+1},
\end{aligned}
$$

where (38) is the usual feasibility condition given a measure 1 each of buyers and sellers, and (37) comes from (34) for buyers (sellers do not hold $k$, as the return is too low, given they do not value liquidity). Note that on the RHS of (35), the $\omega$ in $v^{\prime}(q)$ cancels with $\Lambda_{b}$. In this quasi-linear case, $q$ does not depend on $\omega$ or $K$.

Moreover, $D$ does not affect $\left(q, x, K_{+1}, N\right)$, since it does not appear in (35)(38). Again, changes in $D$ lead to an endogenous response in real balances that keeps $L$ constant. So $D$ is still neutral. Changes in $\chi$, however, are not: in steady state, $\partial K / \partial \chi>0$, and $\partial x / \partial \chi>0$ if $K$ and $N$ are normal inputs, while $\partial N / \partial \chi$ is ambiguous due to wealth and substitution effects. Changes in $\chi$ do not affect $q$ in this specification, but they affect the CM allocation, because when $K$ is better able to relax the liquidity constraint investment increases. ${ }^{21}$ That did not

\footnotetext{
${ }^{21}$ This is related to the Mundell-Tobin effect, although it is actually the higher pledgeability of $K$ that is driving the increase in investment, not a lower return on $M$.
} 


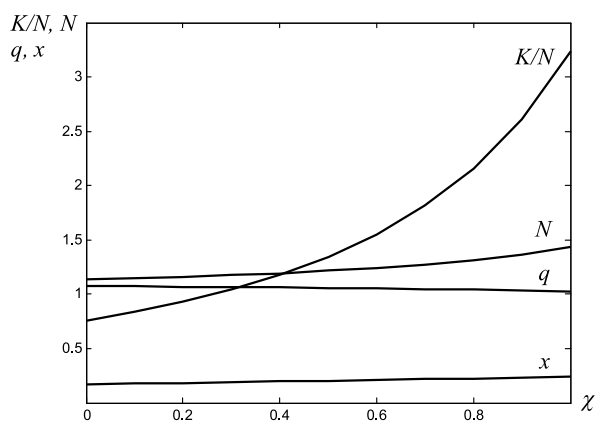

(a) Effects of $\chi$.

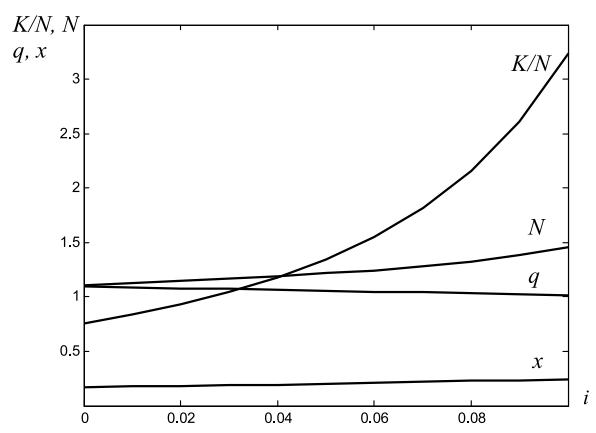

(b) Effects of $i$.

FIGURE 5.-A numerical example.

happen in Section 6.4 because the asset was in fixed supply and it was not a factor of production. Still, while $\chi$ might matter, in monetary equilibrium, $D$ does not.

Consider next $U^{b}(x, 1-\ell)=x^{\sigma}(1-\ell)^{1-\sigma}$ and $U^{s}(x, 1-\ell)=\tilde{U}(x)-\ell$, plus bargaining with $\theta=1, v(q)=c(q) / \Lambda_{s}$. Then (14) becomes $u^{\prime}(q)=(1+$ $i / \alpha) c^{\prime}(q) \Lambda_{b} / \Lambda_{s}$, but $\Lambda_{b} / \Lambda_{s}$ does not cancel since buyers do not have quasilinear utility. The FOC's from the CM imply $\Lambda_{b}=\omega^{\sigma-1} \sigma^{\sigma}(1-\sigma)^{1-\sigma}$ and $\Lambda_{s}=$ $\omega^{-1}$, and hence

$$
u^{\prime}(q)=(1+i / \alpha) \omega^{\sigma} \sigma^{\sigma}(1-\sigma)^{1-\sigma} c^{\prime}(q) .
$$

Now $q$ is decreasing in $\omega$ and $\chi$ (if we switch buyer and seller preferences, then $q$ is increasing in $\omega$ and $\chi$ ). The intuition is this: When $b$ transfers purchasing power to $s$, the parties value it according to $\Lambda_{b}$ and $\Lambda_{s}$. Changes in $\chi$ affect $K$, and hence $\omega$, and if $\omega$ affects $\Lambda_{b}$ and $\Lambda_{s}$ differently, the terms of trade tilt. Figures 5(a) and (b) show $K / N, N, q$, and $x$ as functions of $\chi$ and $i$ for an example (see Gu et al. (2014) for details). This is different from the quasi-linear case, where $q$ is independent of $\chi$, illustrating how Wong's (2015) more general preferences can affect results. While this is interesting, and helps motivate our specification, rather than the simpler quasi-linear case, we think, the main point is that changes in $D$ are still neutral in monetary equilibrium.

\subsection{Dynamics}

Here we characterize the dynamics in the benchmark specification, where money is the only asset. The FOC w.r.t. $\hat{m}$ evaluated at $m=M$ is now written as follows: If $\phi_{+1} M_{+1}+D<v\left(q^{*}\right)$, then

$$
\phi=\beta \phi_{+1}\left\{\alpha\left[\frac{u^{\prime}\left(q_{+1}\right)}{v^{\prime}\left(q_{+1}\right)}-1\right]+1\right\} \quad \text { and } \quad q_{+1}=v^{-1}\left(\phi_{+1} M_{+1}+D\right) ;
$$


and if $\phi_{+1} M_{+1}+D \geq v\left(q^{*}\right)$, then

$$
\phi=\beta \phi_{+1} \quad \text { and } \quad q_{+1}=q^{*} .
$$

Note $q$ can never exceed $q^{*}$, but if next period real balances are enough to get $q^{*}$, then the liquidity premium vanishes and $\phi=\beta \phi_{+1}$. In this case, buyers may spend $p<\phi_{+1} M_{+1}+D$.

Let $z=\phi M$ and rewrite (40) and (41) as $z=g\left(z_{+1} ; D\right)$, where

$$
g\left(z_{+1} ; D\right) \equiv\left\{\begin{array}{l}
\frac{\beta z_{+1}}{1+\pi}\left\{\alpha\left[\frac{u^{\prime} \circ v^{-1}\left(z_{+1}+D\right)}{v^{\prime} \circ v^{-1}\left(z_{+1}+D\right)}-1\right]+1\right\} \\
\text { if } z_{+1}+D<v\left(q^{*}\right) \\
\frac{\beta z_{+1}}{1+\pi} \\
\text { if } z_{+1}+D \geq v\left(q^{*}\right) .
\end{array}\right.
$$

Given policy, which here we take to be the rate of monetary expansion $\pi$, a monetary equilibrium is a (nonnegative, bounded) sequence $\left\{z_{t}\right\}$ satisfying this system, where at every date $q=v^{-1}(z+D)$ if $z+D<v\left(q^{*}\right)$, and $q=q^{*}$ otherwise. Assume $1+\pi>\beta$ and $D<v\left(q_{i}\right)$, as required for monetary equilibrium, where $q_{i} \in\left(0, q^{*}\right)$ is the unique monetary steady state and $z_{i}=v\left(q_{i}\right)-D$. There is also a nonmonetary steady state with $q=v^{-1}(D)$ and $z=0$.

We can also write the dynamic system in terms of total liquidity, $L=z+D$, as $L=\tilde{g}\left(L_{+1} ; D\right)$, where

$$
\tilde{g}\left(L_{+1} ; D\right) \equiv\left\{\begin{array}{l}
\frac{\beta\left(L_{+1}-D\right)}{1+\pi}\left\{\alpha\left[\frac{u^{\prime} \circ v^{-1}\left(L_{+1}\right)}{v^{\prime} \circ v^{-1}\left(L_{+1}\right)}-1\right]+1\right\}+D \\
\quad \text { if } L_{+1}<v\left(q^{*}\right), \\
\frac{\beta\left(L_{+1}-D\right)}{1+\pi} \\
\quad \text { if } L_{+1} \geq v\left(q^{*}\right) .
\end{array}\right.
$$

At the steady state, $L_{i}=v\left(q_{i}\right)$ and

$$
\left.\frac{\partial L}{\partial L_{+}}\right|_{L_{i}}=1+\frac{v\left(q_{i}\right)-D}{1+i} \frac{\alpha u^{\prime \prime}\left(q_{i}\right)-(\alpha+i) v^{\prime \prime}\left(q_{i}\right)}{v^{\prime}\left(q_{i}\right)^{2}},
$$

after using the Fisher equation. Notice $g$ crosses the $45^{\circ}$ line from above and $g^{-1}$ crosses it from below, as shown in Figure 6(a). ${ }^{22}$ Similarly for $\tilde{g}$ in Figure 6(b). Also shown is what happens as we vary $D$. Notice in Figure 6(a) that $g\left(z_{+1} ; D_{1}\right)<g\left(z_{+1} ; D_{0}\right)$ when $D_{1}>D_{0}$, and similarly for $\tilde{g}$ in Figure 6(b).

\footnotetext{
${ }^{22}$ This example uses $v(q)=c(q)=q^{1+\sigma} /(1+\sigma), u(q)=A\left[(q+b)^{1-\gamma}-b^{1-\gamma}\right] /(1-\gamma)$, where $\sigma=0, \gamma=1.6, A=0.1, b=0.1, \alpha=1$, and $(1+\pi) / \beta=1.2$. While $g$ and $\tilde{g}$ happen to be monotone here, that is not generally the case.
} 


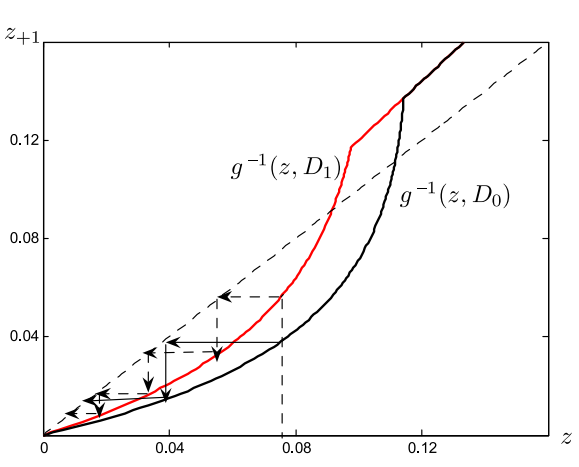

(a) Dynamics of $z$.

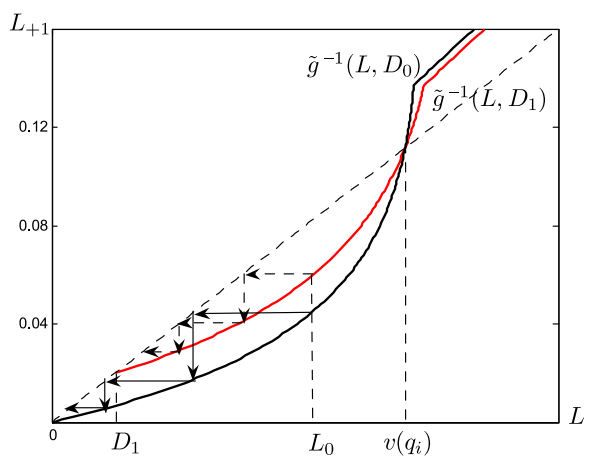

(b) Dynamics of $L$.

FIGURE 6.-Dynamic equilibria.

In Figure 6(a), starting from any $z_{0} \in\left(0, z_{i}\right)$, there is an equilibrium converging to the nonmonetary equilibrium; there is no equilibrium starting at $z_{0}>z_{i}$. Similarly for Figure 6(b), from which it is also clear that if we start at the same $L_{0}<v\left(q_{i}\right)$, the path for $L$ generated by $D_{1}$ is above the path generated by $D_{0}<D_{1}$, and so welfare is higher with $D_{1}$. However, there is still an equilibrium where credit does not matter: the steady state $q_{i}$. Hence we can still say that credit is inessential, but we can only say $D$ is neutral in the stationary monetary equilibrium. The reason credit is not neutral in nonstationary equilibria is simple: in the long run, the value of money goes to 0 , and since $D$ matters in a nonmonetary equilibrium, it matters on the transition to a nonmonetary equilibrium. ${ }^{23}$

\section{CONCLUSION}

The above material has been a progress report on our research into interactions between money and credit. Theoretically, this is interesting because it is not trivial to embed money, let alone money and credit, into equilibrium theory. ${ }^{24}$ It is also relevant from a policy perspective. For various specifications, we found that there are equilibria where both money and credit are used, but

\footnotetext{
${ }^{23}$ As is standard, more complex dynamics can emerge for $\partial L /\left.\partial L_{+}\right|_{L_{i}}<-1$, where one can show there are cyclic, chaotic, and stochastic (sunspot) equilibria using textbook methods (e.g., Azariadis (1993)). As $D$ increases, these equilibria disappear, so again $D$ affects nonstationary equilibria.

${ }^{24}$ Of course, one can impose cash-in-advance constraints, put assets in the utility function, or adopt some other ad hoc approach. We do not consider that appropriate-it is giving up rather than addressing the issue. For our purposes, moreover, one ought not assume missing markets, incomplete contracts, sticky prices, etc., although something like that may emerge as an outcome of frictions in the environment. As Townsend (1988) said, "theory should explain why markets sometimes exist and sometimes do not, so that economic organization falls out in the solution to the mechanism design problem." As regards money and credit, in particular, Townsend (1989)
} 
whenever money is valued, credit is inessential and changes in the debt limit $D$ are neutral. In such a situation, real balances adjust endogenously to changes in $D$, keeping total liquidity the same. Hence, the private sector (the market) finds a way to self-correct the consequences of changes in $D$. The results hold for a general class of pricing mechanisms, for secured or unsecured credit, for debt limits that can be relaxed at a cost, and for exogenous or endogenous limits to debt and deflation. They also hold with heterogeneous agents as long as those constrained by $D$ choose $\hat{m}>0$.

There are exceptions. One has some buyers constrained by $D$ but still choosing $\hat{m}=0$. With secured credit, pledgeability $\chi$ does not matter if collateral is in fixed supply, but can matter if it is reproducible and it is a factor of production; still, even if $\chi$ matters, $D$ does not. With endogenous policy and debt limits, a change in parameters impinging on $D$ might affect the bounds on feasible $i$, and then policy might want to or have to respond, but even in such cases it is the change in $i$ that matters, and not the change in $D$. Some results are overturned by heterogeneous monitoring that leads to different sellers treating alternative payment instruments differently, although we might mention that this can also overturn Modigliani-Miller, Kareken-Wallace, or Ricardian equivalence. Like those irrelevancy propositions, even if one can find specifications where the baseline results do not hold, we think they nevertheless contain an element of truth. Moreover, it is not as though mainstream macroeconomists that claim credit matters typically have heterogeneous monitoring and alternative payment instruments in their models.

More generally, it seems important to know what kinds of assumptions may or may not make credit matter. If economists want to argue that credit conditions are important, they should be able to articulate how the assumptions in the models presented above are violated, and they might check what happens in the models they use once money is introduced. Undoubtedly, some people working in other camps are aware of this issue, and we understand that what is important is not only whether money is part of the model, but also how it is introduced and how the prices are determined. ${ }^{25}$ We also emphasize the following: even if our strong neutrality results do not hold, as in some of

asked "Can we find a physical environment in which currency-like objects play an essential role in implementing efficient allocations? Would these objects coexist with... credit?" Questions like these interest and motivate us. See Lagos, Rocheteau, and Wright (2015) and references therein for more on methodology.

${ }^{25}$ Bernanke, Gertler, and Gilchrist (1999) is an example of what we have in mind. For what it is worth, our results obviously require flexible prices, in the sense that this is the way $\phi M$ adjusts endogenously to a fall in $D$. To put this in perspective, consider the welfare theorems. Given a set of parameters, equilibrium is efficient. Now change parameters and ask if the equilibrium is still efficient. Generally, the answer is no if prices are forced to be the same, but we do not find this a compelling critique of the welfare propositions. Indeed, to us, it is like saying that Ricardian equivalance fails if household saving is exogenous-it may be true, but it is not very interesting. The economy can only self-correct if we do not put artificial restrictions on its ability to self-correct. 
the exceptional cases discussed above, clearly, the results of changes in credit conditions are different in monetary and in nonmonetary economies, because currency provides a substitute for credit, and this should be taken into account in policy analysis.

Still more generally, we think monetary policy analysis should proceed using theories that try to take the exchange/payment/settlement processes seriously, which is not a good description of most policy analysis these days. Perhaps this paper will suggest to some people alternative ways to proceed. As a final word, we relate these sentiments to our use of the term "redux" in the title. As suggested by the epigraph, from Robbins, interest in the relationship between money and credit has a long history and has been the subject of much interesting work, but recent macro and monetary economics has moved in a different direction, quite often neglecting money entirely, perhaps especially in New Keynesian theory and policy discussions. We think it might be good to bring money back and revisit interactions between money and credit. This paper has been our attempt to show how it can be done and how it makes a difference.

\section{APPENDIX}

Here we provide proofs for a few results that are not obvious, and sketch the model with endogenous policy and debt limits when punishment involves allowing deviators to continue in the DM but only using cash.

PROOF OF LEMMAS 1 AND 2: Consider first buyers. They are constrained, $q<q^{*}$, in stationary monetary equilibrium. Differentiating (3)-(4), we get

$$
\left[\begin{array}{ccc}
\omega U_{11}^{b}-U_{21}^{b} & -\omega U_{12}^{b}+U_{22}^{b} & 0 \\
-\phi U_{11}^{b} & \phi U_{12}^{b} & \beta \phi_{+1}^{2} V_{b}^{\prime \prime} \\
1 & -\omega & \phi
\end{array}\right]\left[\begin{array}{c}
d x \\
d \ell \\
d \hat{m}_{b}
\end{array}\right]=\left[\begin{array}{c}
0 \\
0 \\
d A
\end{array}\right],
$$

where $V_{b}^{\prime \prime}$ is well defined from (10) and the assumptions on $v$. The determinant is $\Delta_{1}=\beta \phi_{+1}^{2} V_{b}^{\prime \prime}\left(\omega^{2} U_{11}^{b}-2 \omega U_{21}^{b}+U_{22}^{b}\right)>0$, and $\partial \hat{m}_{b} / \partial A=\Delta_{1}^{-1} \phi\left|U^{b}\right|=0$, since $\left|U^{b}\right|=0$ by Assumption 1 . Hence $\hat{m}_{b}$ is independent of $A$.

Let $\Lambda_{b}(A)=U_{1}^{b}[x(A), 1-\ell(A)]$. Then

$$
\begin{aligned}
\frac{\partial U_{1}^{b}}{\partial A} & =U_{11} \frac{\partial x}{\partial A}-U_{12} \frac{\partial \ell}{\partial A} \\
& =\Delta_{1}^{-1} \beta \phi_{+}^{2} V_{b}^{\prime \prime}\left[U_{11}^{b}\left(-\omega U_{12}^{b}+U_{22}^{b}\right)+U_{12}^{b}\left(\omega U_{11}^{b}-U_{22}^{b}\right)\right]=0 .
\end{aligned}
$$

By (3), $U_{2}^{b}(\cdot)=\Lambda_{b} \omega$. By the envelope theorem, $W_{b}^{\prime}(\cdot)=\Lambda_{b}$. That takes care of buyers in monetary equilibrium. In a nonmonetary equilibrium, $\partial U_{1}^{b} / \partial A=$ $-\Delta_{0}^{-1}\left|U^{b}\right|=0$, where $\Delta_{0}=-\left(\omega^{2} U_{11}^{b}-2 \omega U_{21}^{b}+U_{22}^{b}\right)>0$. Again, $U_{1}^{b}(\cdot)=\Lambda_{b}$, etc. This completes the argument for buyers. The argument for sellers is similar.

Q.E.D. 
ProOf OF Lemma 4: Suppose $L \geq p^{*}$. Then $V_{b}^{\prime}(\cdot)=W_{b}^{\prime}(\cdot)=1$, because the terms of trade $(p, q)=\left(p^{*}, q^{*}\right)$ are independent of $L$ when the constraint is slack. By the FOC for $\hat{m}$ at equality, $\phi=\beta \phi_{+1}$. Since $\phi / \phi_{+1}=1+\pi$, this contradicts $\pi>\beta-1$. In the limiting case of the Friedman rule, $\pi=\beta-1$, money can be held even if the constraint is slack, but in this case money does not accomplish anything-payoffs would be the same if $M=0$.

Q.E.D.

Alternative Punishment: Suppose now that if an agent is caught reneging, he is banned from using credit in the DM, but can continue using cash. The punishment payoff is

$$
\begin{gathered}
\underline{W}(\phi m)=\max _{x, \ell, \hat{m}, q}\left\{U^{b}(x, 1-\ell)+\beta \alpha\left[u(q)-\Lambda_{b} v(q)\right]+\beta \underline{W}\left(\phi_{+} \hat{m}\right)\right\} \\
\text { s.t. } \phi m+\omega \ell=x+\phi \hat{m} \quad \text { and } \quad v(q) \leq \phi_{+1} \hat{m} .
\end{gathered}
$$

In monetary equilibrium, this reduces to

$$
\underline{W}(\phi m)=\frac{1+r}{r} U_{0}+\phi m \Lambda_{b}-\Lambda_{b} \frac{i}{r} v\left(q_{i}\right)+\frac{\alpha}{r}\left[u\left(q_{i}\right)-\Lambda_{b} v\left(q_{i}\right)\right] .
$$

The policy constraint reduces to $\left(r+\mu_{T}\right) T \leq \mu_{T} i D$. Given an incentivefeasible policy, the debt repayment constraint is again $d \leq \Phi(D)$, where now

$$
\Phi(D) \equiv \begin{cases}\mu_{D} D+\mu_{D} \frac{i-r}{r} v\left(q_{i}\right) & \text { if } D<v\left(q_{i}\right), \\ \xi\left[u \circ v^{-1}\left(\Lambda_{b} D\right) / \Lambda_{b}-D\right] & \text { if } v\left(q_{i}\right) \leq D<v\left(q^{*}\right), \\ \xi\left[u\left(q^{*}\right) / \Lambda_{b}-v\left(q^{*}\right)\right] & \text { if } v\left(q^{*}\right) \leq D,\end{cases}
$$

if we select the monetary equilibrium when it exists. A fixed point admitting monetary equilibrium solves

$$
D=\frac{\mu_{D}}{1-\mu_{D}} \frac{i-r}{r} v\left(q_{i}\right),
$$

which satisfies $0 \leq D<v\left(q_{i}\right)$ iff $r \leq i<r / \mu_{D}$. The tax payment constraint requires $\left(1-\mu_{T}\right) T \leq \mu_{T}(i-r) v\left(q_{i}\right) / r$, which is equivalent to $i \geq r$. Therefore, $r \leq i<r / \mu_{D}$ is necessary and sufficient for a monetary equilibrium. In this case, deflation is simply not feasible.

Q.E.D.

\section{REFERENCES}

AiYAgari, S. R., AND S. Williamson (1999): "Credit in a Random Matching Model With Private Information," Review of Economic Dynamics, 2, 36-64. [15]

Aliprantis, C., G. CAMERA, AND D. PuZzello (2007): "Anonymous Markets and Monetary Trading," Journal of Monetary Economics, 54, 1905-1928. [2]

Alvarez, F., AND U. JeRmann (2000): "Efficiency, Equilibrium, and Asset Pricing With Risk of Default," Econometrica, 68, 775-798. [14] 
Amendola, N., AND L. Ferraris (2013): "Money and Limited Enforcement in Multilateral Exchange," Report. [13]

ANDOLFATTO, D. (2013): "Incentive-Feasible Deflation," Journal of Monetary Economics, 60, 383-390. [3,6]

ARAujo, L., AND T. Hu (2014): "Optimal Monetary Policy When Money and Credit Are Essential," Report. [2,8,21]

ARAujo, L., AND R. MinetTi (2011): "On the Essentiality of Banks," International Economic Review, 52, 679-691. [2]

Araujo, L., B. Camargo, R. Minetti, and D. Puzzello (2012): "The Essentiality of Money in Environments With Centralized Trade," Journal of Monetary Economics, 59, 612-621. [2]

ARuoba, S. B., G. RocheteAU, AND C. WALler (2007): "Bargaining and the Value of Money," Journal of Monetary Economics, 54, 2636-2655. [8]

AZARIADIS, C. (1993): Intertemporal Macroeconomics. Cambridge, MA: Blackwell. [26]

Berentsen, A., AND C. WAller (2011): "Outside versus Inside Bonds: A ModiglianiMiller Type Result for Liquidity Constrained Economies," Journal of Economic Theory, 146, 1852-1887. [2,21]

Berentsen, A., G. CAmera, ANd C. WAller (2007): "Money, Credit and Banking,” Journal of Economic Theory, 135, 171-195. [3,15]

BERNANKE, B., AND M. GERTLER (1989): "Agency Costs, Net Worth, and Business Fluctuations," American Economic Review, 79, 14-31. [3]

Bernanke, B., M. GerTLER, AND S. Gilchrist (1999): “The Financial Accelerator in a Quantitative Business Cycle Framework," in Handbook of Macroeconomics, ed. by J. B. Taylor and M. Woodford. Amsterdam: North-Holland. [27]

Bethune, Z., M. ChOI, AND R. Wright (2015): “Frictional Goods Markets,” Report. [3,18]

Bethune, Z., G. Rocheteau, AND T.-W. Hu (2014): "Dynamic Indeterminacy in Credit Economies," Report. [14]

BEwLEY, T. (1980): “The Optimal Quantity of Money," in Models of Monetary Economies, ed. by J. Kareken and N. Wallace. Minneapolis: Federal Reserve Bank of Minneapolis. [3]

CARAPElla, F., AND S. Williamson (2014): "Credit Markets, Limited Commitment, and Government Debt," Review of Economic Studies, 82, 963-990. [14]

Cavalcanti, R., And N. Wallace (1999): "A Model of Private Banknote Issue," Review of Economic Dynamics, 2, 104-136. [13]

ChIU, J., AND M. Molico (2010): "Endogenously Segmented Markets in a Search Theoretic Model of Monetary Exchange," Journal of Monetary Economics, 57, 428-438. [7] 487-512. [7]

DiAmond, D., AND P. DybVIG (1983): "Bank Runs, Deposit Insurance, and Liquidity,” Journal of Political Economy, 91, 401-419. [3]

Geromichalos, A., J. LiCARI, AND J. Lledo (2007): "Asset Prices and Monetary Policy," Review of Economic Dynamics, 10, 761-779. [21]

GERTLER, M., AND N. KIYOTAKI (2010): "Financial Intermediation and Credit Policy in Business Cycle Analysis," in Handbook of Monetary Economics, ed. by B. Friedman and M. Woodford. Amsterdam: North-Holland. [3]

Gomis-Porqueras, P., AND D. SANChes (2013): "Optimal Monetary Policy in a Model of Money and Credit," Journal of Money, Credit and Banking, 45, 701-729. [21]

Gu, C., AND R. WRIGHT (2015): “Monetary Mechanisms,” Report. [8,10,12,18,19]

Gu, C., F. Mattesini, C. Monnet, And R. Wright (2013a): "Banking: A New Monetarist Approach," Review of Economic Studies, 80, 636-662. [2,6,13]

$13,14,19]$

Gu, C., F. MAtTESini, AND R. Wright (2014): “Money and Credit Redux,” Report. [8,24]

HE, P., L. HuANG, AND R. WRIGHT (2005): "Money and Banking in Search Equilibrium," International Economic Review, 46, 637-670. [3] 
(2008): "Money, Banking and Monetary Policy,” Journal of Monetary Economics, 55, 1013-1024. [3]

Hu, T.-W., J. Kennan, AND N. Wallace (2009): "Coalition-Proof Trade and the Friedman Rule in the Lagos-Wright Model," Journal of Political Economy, 117, 116-137. [8,12]

KAHN, C., AND W. ROBERDS (2008): “Credit and Identity Theft," Journal of Monetary Economics, 55, 251-264. [3]

KAHN, C., J. MCANDREwS, AND W. Roberds (2005): “Money Is Privacy," International Economic Review, 46, 377-399. [3]

Kehoe, T., And D. Levine (1993): “Debt-Constrained Asset Markets," Review of Economic Studies, 60, 865-888. [2-4,6]

_ (2001): "Liquidity Constrained Markets versus Debt Constrained Markets," Econometrica, 69, 575-598. [4]

KiYOtAKI, N., AND J. H. Moore (1997): "Credit Cycles," Journal of Political Economy, 105, 211-248. [2,3,21]

KIYOTAKI, N., AND R. Wright (1989): “On Money as a Medium of Exchange,” Journal of Political Economy, 97, 927-954. [4]

(1993): "A Search-Theoretic Approach to Monetary Economics," American Economic Review, 83, 63-77. [4]

Kocherlakota, N. (1998): “Money Is Memory,” Journal of Economic Theory, 81, 232-251. [2,4, 16]

Kocherlakota, N., AND N. WALlaCe (1998): "Incomplete Record Keeping and Optimal Payment Arrangements," Journal of Economic Theory, 81, 272-289. [13]

LAGOS, R., AND G. RocheteAu (2008): "Money and Capital as Competing Media of Exchange," Journal of Economic Theory, 142, 247-258. [21]

LAGOS, R., AND R. WRight (2005): "A Unified Framework for Monetary Theory and Policy Analysis," Journal of Political Economy, 113, 463-484. [3]

LAGOS, R., G. RocheTEAU, AND R. WRIGHT (2015): "Liquidity: A New Monetarist Perspective," Journal of Economic Literature (forthcoming). [2,27]

LESTER, B., A. PosTLEWAITE, AND R. WRIGHT (2012): "Liquidity, Information, Asset Prices and Monetary Policy," Review of Economic Studies, 79, 1209-1238. [21]

LotZ, S., AND C. ZhANG (2013): "Money and Credit as Means of Payment: A New Monetarist Model," Report. [21]

LUCAS, R. E., AND N. STOKEY (1987): "Money and Interest in a Cash-in-Advance Economy," Econometrica, 55, 491-513. [3]

MILlS, D. (2007): "A Model in Which Outside and Inside Money Are Essential," Macroeconomic Dynamics, 11, 347-366. [2]

Nosal, E., AND G. RocheTEAU (2011): Money, Payments, and Liquidity. Cambridge, MA: MIT Press. [2,3,20]

NosAL, E., Y. WONG, AND R. WRIGHT (2014): "More on Middlemen: Equilibrium Entry and Efficiency in Markets With Intermediation," Report. [2]

RocheteaU, G., AND R. Wright (2005): "Money in Search Equilibrium, in Competitive Equilibrium, and in Competitive Search Equilibrium," Econometrica, 73, 175-202. [3,5,8]

SANCHES, D., AND S. WILLIAMSON (2010): "Money and Credit With Limited Commitment and Theft," Journal of Economic Theory, 145, 1525-1549. [3,13,21]

SHI, S. (2006): "Viewpoint: A Microfoundation of Monetary Economics," Canadian Journal of Economics, 39, 364-388. [2]

TOWNSEND, R. (1987): "Arrow-Debreu Programs as Microfoundations of Macroeconomics," in Econometric Soc. Monographs, Vol. 12, ed. by T. Bewley. Cambridge: Cambridge University Press. [2]

__ (1988): “Models as Economies,” Economic Journal, 98, 1-24. [2,26]

(1989): "Currency and Credit in a Private Information Economy," Journal of Political Economy, 97, 1323-1344. [26] 
VENKATESWARAN, V., AND R. WRIGHT (2013): "Pledgeability and Liquidity: A New Monetarist Model of Financial and Macroeconomic Activity," in NBER 2013 Macro Annual, Vol. 28. Cambridge, MA: NBER, 227-270. [23]

VON MISES, L. (1953): The Theory of Money and Credit (New Ed.). New Haven: Yale University Press. [1]

Wallace, N. (1980): “The Overlapping Generations Model of Fiat Money," in Models of Monetary Economies, ed. by J. Kareken and N. Wallace. Minneapolis: Federal Reserve Bank of Minneapolis. [3]

$[2]$ (2001): “Whither Monetary Economics?," International Economic Review, 42, 847-869.

(2010): “The Mechanism Design Approach to Monetary Theory," in Handbook of Monetary Economics, ed. by B. Friedman and M. Woodford. Amsterdam: North-Holland. [2]

(2013): "An Alternative to New-Keynesian Models for the Study of Optimal (Monetary) Policy," Report. [6]

Williamson, S. (2012): "Liquidity, Monetary Policy, and the Financial Crisis: A New Monetarist Approach," American Economic Review, 102, 2570-2605. [3]

Williamson, S., AND R. Wright (2010a): "New Monetarist Economics: Methods," FRB St Louis Review. [2]

(2010b): "New Monetarist Economics: Models," in Handbook of Monetary Economics, ed. by B. Friedman and M. Woodford. Amsterdam: North-Holland. [2]

WONG, R. (2015): "A Tractable Monetary Model Under General Preferences," Review of Economic Studies (forthcoming). [3,5,7,24]

Dept. of Economics, University of Missouri, Columbia, MO 65211, U.S.A.; guc@missouri.edu,

Dept. of Economics and Law, University of Rome Tor-Vergatta, Rome, Italy; fabri.mattesini@gmail.com,

$$
\text { and }
$$

Federal Reserve Bank of Chicago, 230 S La Salle St., Chicago, IL 60604, U.S.A., Federal Reserve Bank of Minneapolis, 90 Hennepin Ave., Minneapolis, MN 55401, U.S.A., Wisconsin School of Business, University of WisconsinMadison, 975 University Ave., Madison, WI 53706, U.S.A., and NBER; rwright@ bus.wisc.edu. 